\title{
TREATMENT OF ACUTE BRONCHIOLITIS;
}

\section{THE ROLE OF RESPIRATORY VIRUSES AND}

\section{ALLERGIC DISEASE}

\author{
Håvard Ove Skjerven
}

University of Oslo, Institute of Clinical Medicine

$\&$

Oslo University Hospital, Department of Paediatrics

$\&$

ORAACLE

Oslo Research group of Asthma and Allergy in Childhood; the Lung and Environment

2016
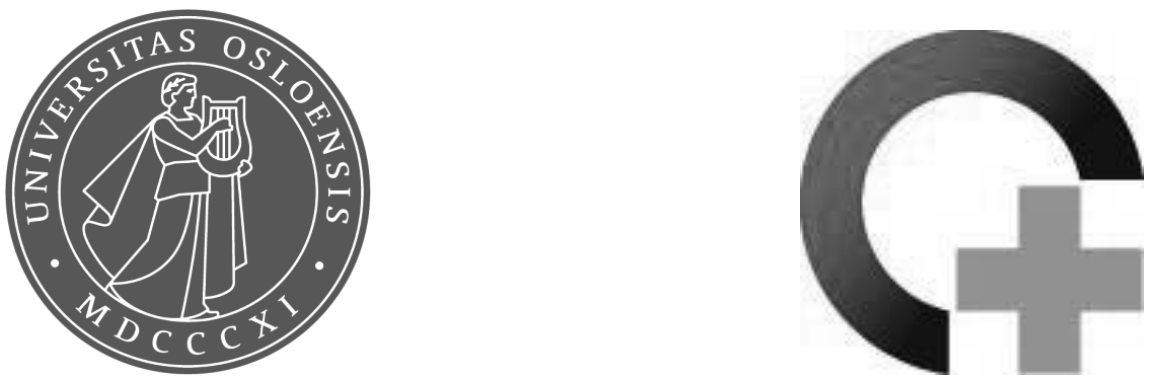
(c) Håvard Ove Skjerven, 2016

Series of dissertations submitted to the Faculty of Medicine, University of Oslo

ISBN 978-82-8333-203-2

All rights reserved. No part of this publication may be reproduced or transmitted, in any form or by any means, without permission.

Cover: Hanne Baadsgaard Utigard

Printed in Norway: 07 Media AS - www.07.no 


\section{Table of Contents}

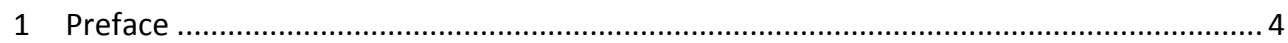

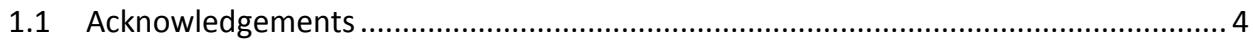

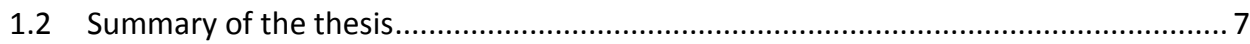

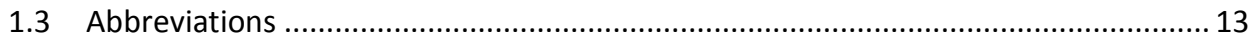

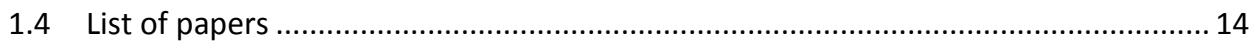

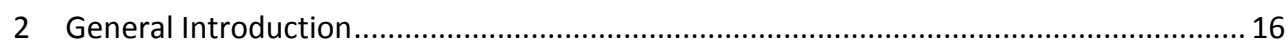

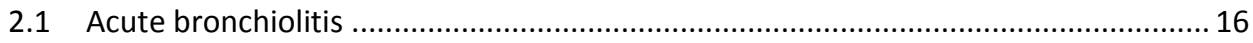

2.2 Treatment of acute bronchiolitis................................................................... 19

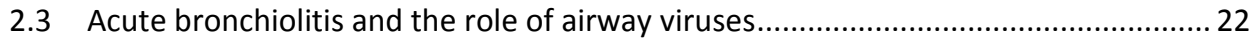

2.4 Allergic disease and treatment response in acute bronchiolitis ............................. 25

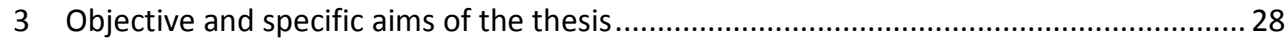

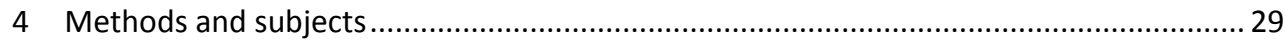

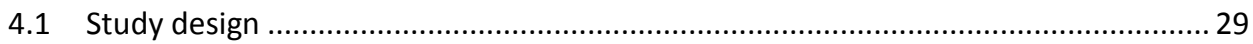

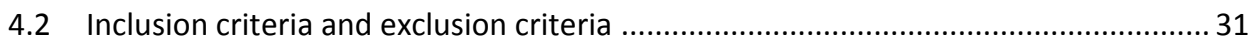

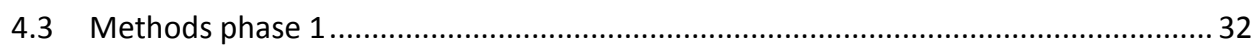

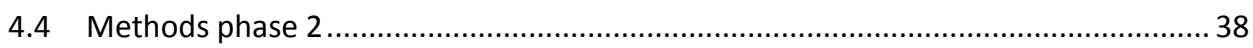

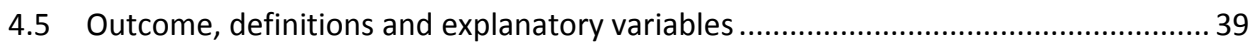

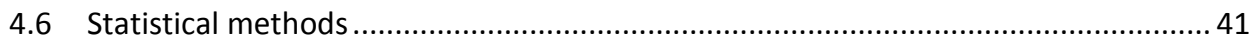

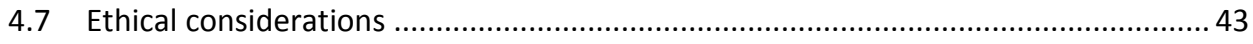

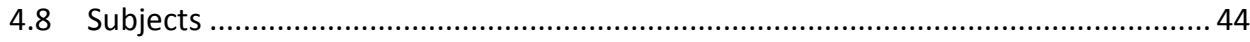

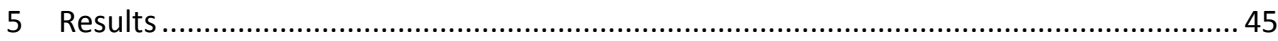

5.1 Is inhaled racemic adrenaline effective in acute bronchiolitis in hospitalized infants? (paper \#1) 
5.2 Is inhalation treatment "on demand" superior to "fixed schedule" in acute bronchiolitis in hospitalized infants? (paper \#1)

5.3 What is the role of airway viruses in acute bronchiolitis with respect to severity of disease and treatment response of inhaled adrenaline? (paper \#2).

5.4 What is the role of allergic disease, present at the time of the acute bronchiolitis or later, with respect to treatment response? (paper $\# 1,3)$................................................ 59

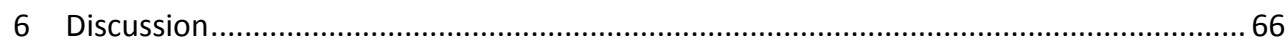

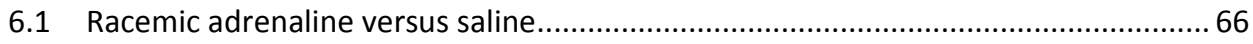

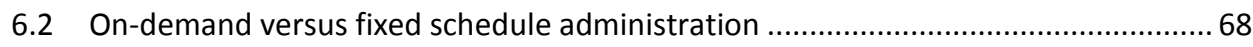

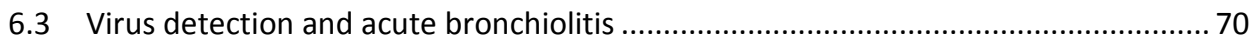

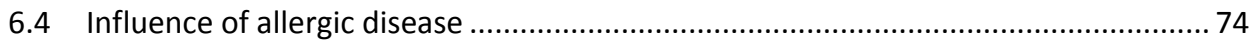

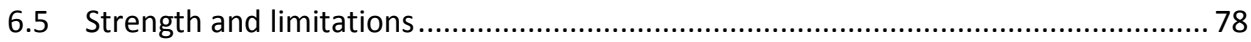

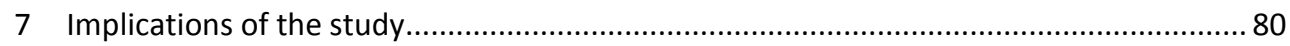

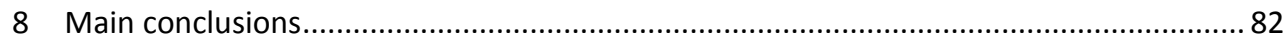

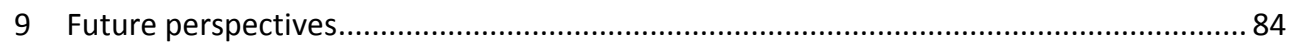

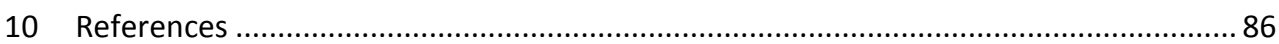

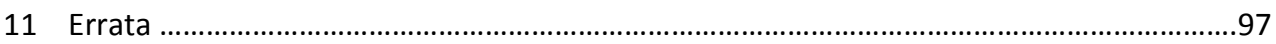

Paper \#1-3 


\section{Preface}

\subsection{Acknowledgements}

This project was only possible thanks to the dedication of a vast number of health care professionals, patients and parents. I will forever be grateful for your contributions.

First of all, I would like to thank the parents of the more than 400 participating infants, as well as the patients themselves. I am overwhelmed by your willingness to let your vulnerable loved ones; admitted acutely to hospital with moderate to severe respiratory distress, to take part in a trial that challenged the current practice. Your admirable attitude is crucial for the development of modern medicine; you have my deepest respect.

Behind all the studies of the excellent ORAACLE (Oslo Research group of Asthma and Allergy in Childhood; the Lung and Environment) research group stands my two supervisors; Professor Karin C Lødrup Carlsen and professor Kai-Håkon Carlsen. From the first day Karin introduced me to the concept of this project in 2008 , I have received all the responsibility and support that I could ever ask for. In respect to all aspects of research, the supervision has been at the highest level; from study designing, via applications, procedures, logistics and education of staff through patient recruitment and study completion to scientific interpretation and publication of results, and last but by no means least; always in line with the highest standard of ethics. Karin has an extraordinary working capacity, is a guarantee for the highest quality and has been the undisputable head of this project and my most important mentor. Kai-Håkon has been internationally renowned since his first studies on children with acute bronchiolitis in Oslo back in the 1970's. With his great experience and incredible knowledge of the literature, he sees both the big picture and the important details. 
The unique scientific environment you create within the weekly ORAACLE meetings together with our excellent statistician Petter Mowinckel and all other members (you know who you are) of the group has been essential for the successful development of this project.

This study has taken place in the paediatric departments of eight hospitals in the southeast of Norway; Lillehammer, Elverum, Fredrikstad, Drammen, Tønsberg, Skien, Kristiansand and Oslo. Unfortunately, there is not enough space to name the more than 1000 nurses, doctors and biochemical engineers that have been hands on the study participants during the two winter seasons, 24 hours a day, the study was run. The local principal investigators was, of course, crucial with their great enthusiasm and work-capacity, but with no financial compensation; Jon Olav Hunderi, Leif Bjarte Rolfsjord, Hanne Engen, Jon Lunde, Leif Eskedal, Truls Vikin, Marius Haavaldsen, Sabine K Brugmann-Pieper, Christian Siva, Anne Charlotte Brun, Eline Synøve Vold-Engesli and Cecilie H Karsten. The management at all the participating paediatric departments deserves to be honoured for their positive attitude to clinical research and for facilitating this study mainly with internal resources.

The follow-up study was also performed locally by, in addition to the already mentioned Rolfsjord, Hunderi, Lunde and Engen; Bente Kvenshagen, Marianne Hanneborg Aas, Cathrine Midgaard and Edin Dizdarevic, with support from our core crew consisting of Teresa Løvold Berents, Karen Eline Stensby Bains and Live Nordhagen. Thank you all.

Viral analyses were carried out with state-of-the-art procedures by Spyridon Megremis at the University of Athens, under the supervision of Professor Nikos Papadopoulos. Thank you very much for both carrying out the analyses and for collaborating in the interpretation. 
The Medicines for Children Network, Norway, should be recognized for their financial contribution to research nurses in parts of the study.

The University of Oslo granted me a 5 years combined research and teaching fellowship, which I entered less than a month prior to inclusion of the first patient in the study.

Obviously, this was absolutely crucial for the study to be performed. For the past six months I have held a combined clinical and research position within the Section of Paediatric Lung and Allergy at Oslo University Hospital. I want to thank the head of this section, Iren Matthews, for employing me and providing me the time to bring this to completion.

Finally, I will be in serious debt to my dear wife Ingvild for a long time. For years you have filled the gaps in our family logistics that my work has created. I will always be very grateful for this, and for you being ever encouraging. You and our lovely daughters Anna, Hennie and Mia have without a doubt been my main source of energy during these hard working years.

Oslo, November 2015

Håvard Ove Skjerven 


\subsection{Summary of the thesis}

\section{Introduction}

Acute bronchiolitis is the most common cause of admissions to hospital in infancy. The disease is caused by seasonal epidemics of respiratory viruses, most commonly respiratory syncytial virus (RSV). A prodrome of common cold symptoms is usually present, followed by lower airway symptoms and signs including cough, increased respiratory rate, chest retractions, audible wheeze and crackles. The main reasons for admissions to hospital are feeding impairment with dehydration requiring feeding support and respiratory impairment or failure requiring oxygen and occasionally ventilatory support.

Inhaled bronchodilators are commonly used as treatment for acute bronchiolitis, based on studies showing a symptomatic effect. However, not all studies confirm this effect, and there are few reports on more important clinical outcomes such as the length of hospital stay and the use of supportive care. We are not aware of studies investigating the effect of inhalation strategies (on demand or on a fixed schedule) in infants hospitalized with bronchiolitis.

Viral aetiology has previously shown to be associated with disease severity in some, but not all studies. The methods for detection of viral genomic materials are continuously increasing in sensitivity, leading to a potentially higher detection rate of viruses, with more complex associations to clinical disease. Studies investigating possible modification on the effect of inhaled bronchodilators by viral aetiology have been requested.

Inhaled bronchodilators are important and effective in patients with asthma. Efforts have therefore been made to identify individuals with acute bronchiolitis who may be in the process of developing asthma and related diseases (allergies and atopic eczema) with the 
presumed hypothesis that they may benefit from bronchodilators. However, studies investigating this are lacking.

The following specific aims of the thesis were therefore:

1. Is inhaled racemic adrenaline effective in acute bronchiolitis in hospitalized infants?

2. Is inhalation treatment "on demand" superior to "fixed schedule" in acute bronchiolitis in hospitalized infants?

3. What is the role of airway viruses in acute bronchiolitis with respect to severity of disease and treatment response of inhaled adrenaline?

4. What is the role of allergic disease, present at the time of the acute bronchiolitis or later, with respect to treatment response?

\section{Methods}

We conducted a multicentre, double-blind, randomized clinical trial that included infants with acute bronchiolitis who were admitted to the paediatric departments of eight hospitals in south-eastern Norway from January 2010 through May 2011. In accordance with a twoby-two factorial design, children were randomly assigned to receive inhaled racemic adrenaline or inhaled saline and to receive the assigned treatment on demand or on a fixed schedule.

Nasopharyngeal aspirates were collected at inclusion, frozen and batch-analysed at the University of Athens with PCR analyses. Analyses were performed primarily by crude virus presence and secondarily in regards to high genomic load only, classified semi quantitatively by cluster analyses. 
A follow-up investigation was conducted at two years of age with a particular focus on the development or presence of allergic disease and included a structured parenteral interview, a clinical examination and a skin prick test (SPT).

\section{Results}

Length of stay, use of oxygen supplementation, nasogastric-tube feeding, ventilatory support, and relative improvement in the clinical score from baseline (pre inhalation) were similar in the infants treated with inhaled racemic adrenaline and those treated with inhaled saline ( $P>0.1$ for all comparisons).

On-demand inhalation, as compared with fixed-schedule inhalation, was associated with a significantly shorter mean length of stay (estimated in robust linear regression) -47.6 hours (95\% confidence interval $[\mathrm{Cl}], 30.6,64.6)$ versus 61.3 hours $(95 \% \mathrm{Cl}, 45.4,77.2 ; \mathrm{p}=0.01)-$ as well as less use of oxygen supplementation (in $38.3 \%$ of infants vs. $48.7 \%, p=0.04$ ), less use of ventilatory support (in $4.0 \%$ vs. $10.8 \%, p=0.01$ ), and fewer inhalation treatments (12.0 vs. $17.0, p<0.001)$.

The most commonly detected viruses were Respiratory syncytial virus (RSV)(83\%) and Human rhinovirus (HRV)(34\%). Seven other viruses were present in $8-15 \%$ of the patients. Two viruses or more (maximum seven) were detected in $61 \%$ of the infants. Virus type or coinfection was not associated with disease severity. However, a high genomic load of RSV was associated with longer LOS and increased use of oxygen and ventilatory support. Treatment effect of inhaled adrenaline was not modified by virus type, load or coinfection. Among the 294 infants who attended the 2-year follow-up investigations, the LOS during acute bronchiolitis did not differ significantly between patients who received inhaled 
epinephrine versus saline in the subgroup of infants who developed recurrent bronchial obstruction by age two years $\left(143[48.6 \%], p_{\text {interaction }}=0.40\right)$. However, the presence of atopic eczema or allergic sensitization by the age of two years $(n=77)$ significantly interacted with the treatment effect of inhaled epinephrine $\left(p_{\text {interaction }}=0.02\right)$; the length of stay (mean $80.3 \mathrm{~h}$, 95\% $\mathrm{Cl} 72.8-87.9)$ was significantly shorter in patients receiving inhaled epinephrine versus saline in patients without allergic sensitization or atopic eczema by 2 years $(-19.9 \mathrm{~h},-33.1$ to $-6.3 ; p=0.003)$. No significant differences were found in length of hospital stay in response to epinephrine or saline in children with atopic eczema or allergic sensitization by 2 years (+16.2 h, -11.0 to $43.3 ; p=0.24)$.

\section{Discussion}

Our study showed that for hospitalized children with acute bronchiolitis, inhaled racemic adrenaline was not superior to inhaled saline with regard to length of hospital stay, use of supportive treatment or clinical score. The lack of effect of inhaled adrenaline on length of hospital stay is in line with similar findings related to inhaled salbutamol.

Inhalations given on demand were superior to those administered on a fixed schedule in reducing LOS, with a mean difference in LOS of 13.7 hours. Subgroup analyses showed that this benefit was mainly found in infants less than three months of age. This difference was both clinically and statistically significant and has substantial financial implications. The superiority of the on-demand schedule, in which fewer inhalations were administered, supports the goal of "minimal handling" (allowing infants to sleep, with minimal interruption) in acutely ill infants. 
Two or more respiratory viruses were found in a majority of the patients. Although disease severity was not associated with the identification of virus or the total number of viruses detected, a high genomic load of RSV was associated with a longer length of hospital stay and more use of oxygen and ventilatory support. Neither the presence of viruses, nor the viral genomic load modified the treatment response to inhaled adrenaline.

Contrary to the presumed hypothesis, hospital length of stay for bronchiolitis was not reduced by administration of inhaled racemic adrenaline in infants who subsequently developed atopic eczema, allergic sensitization or recurrent bronchial obstruction.

The effect of bronchodilators in acute bronchiolitis has been the subject of debate. Major guidelines have recommended a restrictive approach based on evidence showing no effect of any bronchodilator on the most clinically relevant parameters such as length of stay and the use of supportive care. Nevertheless, inhaled bronchodilators (including adrenaline) have traditionally been used in most patients with acute bronchiolitis in several regions, including the USA, Finland and Sweden. Sustained frequent use of inhaled bronchodilators is presumably due to a belief in the existence of one or more subgroup(s) of patients that benefit from such treatment. The present study does not support the need of an individual trial of inhaled epinephrine in acute bronchiolitis in children with increased risk of allergic diseases. As a consequence of the present study, adding to the evidence from previous studies, recent updated guidelines in Norway and in America are more restrictive in terms of bronchodilators do not recommend inhaled adrenaline or other bronchodilators for routine treatment of acute bronchiolitis. 


\section{Conclusions}

1. In hospitalized children with acute bronchiolitis, inhaled racemic adrenaline was not superior to inhaled saline.

2. Treatment with inhalations of racemic adrenaline or saline "on demand" was superior to treatment on a fixed schedule in children. Subgroup analyses showed that the benefit was mainly found in infants less than three months of age.

3. Disease severity of acute bronchiolitis was not associated with virus type or coinfection, but a high genomic load of RSV was associated with a longer length of hospital stay and more use of oxygen and ventilatory support. Neither the presence of viruses, nor the viral genomic load modified the treatment response to inhaled adrenaline.

4. Hospital length of stay for bronchiolitis was not reduced by administration of inhaled racemic adrenaline in infants who subsequently developed recurrent bronchial obstruction, atopic eczema or allergic sensitization.

The findings of the present study altogether suggest a strategy of restricted routine use of inhalation therapy by bronchodilators in acute bronchiolitis, and particularly in infants younger than three months of age or in those who develop recurrent obstructive airways disease or other allergic disease. 


\title{
1.3 Abbreviations
}

\author{
RCT Randomized Controlled Trial \\ LOS Length of Stay \\ RSV Respiratory Syncytial Virus \\ HRV Human Rhinovirus \\ SPT Skin Prick Test \\ FluA Influenza A \\ FluB Influenza B \\ MPV Metapneumovirus \\ AdV Adenovirus \\ CoV Coronavirus \\ HBoV Human Bocavirus \\ PIV Parainfluenza virus
}




\subsection{List of papers}

Paper \#1:

Skjerven Håvard Ove, Hunderi Jon Olav Gjengst $\varnothing$, Brügmann-Pieper Sabine Kristin, Brun Anne Charlotte, Engen Hanne, Eskedal Leif, Haavaldsen Marius, Kvenshagen Bente, Lunde Jon, Rolfsjord Leif Bjarte, Siva Christian, Vikin Truls, Mowinckel Petter, Carlsen Kai-Håkon og Carlsen Karin C Lødrup.

Racemic Adrenaline and Inhalation Strategies in Acute Bronchiolitis

The New England Journal of Medicine 2013;368:2286-93

Letter to the Editor, Amendment to Paper \#1:

Skjerven Håvard Ove, Carlsen Kai-Håkon og Carlsen Karin C Lødrup

Inhaled adrenaline in acute bronchiolitis

The New England Journal of Medicine 2013;369:1076-7

Paper \#2

Skjerven Håvard Ove, Megremis Spyridon, Papadopoulos Nikolaos G, Mowinckel Petter, Carlsen Kai-Håkon, Carlsen Karin C Lødrup

Virus type and genomic load in acute bronchiolitis: severity and treatment response with inhaled adrenaline

The Journal of Infectious Diseases. Published online 2015, Oct 27. doi:10.1093/infdis/jiv513 
Paper \#3

Skjerven Håvard Ove, Rolfsjord Leif Bjarte, Berents Teresa Løvold, Engen Hanne, Dizdarevic Edin, Midgaard Cathrine, Kvenshagen Bente, Aas Marianne Hanneborg, Hunderi Jon Olav Gjengst $\varnothing$, Bains Karen Eline Stensby, Mowinckel Petter, Carlsen Kai-Håkon og Carlsen Karin C Lødrup

Allergic diseases and the effect of inhaled epinephrine in children with acute bronchiolitis: follow-up from the randomized, controlled, double-blind, Bronchiolitis ALL trial

Lancet Respiratory Medicine 2015;3:702-8 


\section{General Introduction}

\subsection{Acute bronchiolitis}

Acute bronchiolitis is a lower respiratory tract infection in infancy, is usually viral in origin, with winter epidemics of respiratory syncytial virus being the most common cause. Bronchiolitis was defined by Court $^{1}$ as an:

"Illness mainly affecting infants, especially in the first 6 months of life. Rapid respiration, dyspnoea, wheezing, chest recession, cough, rhonchi and rales are very frequent. Visible distension of the chest and increased pulmonary translucency on the chest radiograph are frequent and of high diagnostic significance. Upper respiratory features, especially nasal discharge and a red pharynx are frequent. Fever is very frequent, but high fever is uncommon." Very frequent is noted as at least $50 \%$ of the children, while frequent refers to $25-50 \%$.

Very young children, particularly those with a history of prematurity, may appear with apnoea as their major symptom. Feeding problems are common. ${ }^{1-3}$

In Northern America the definition of acute bronchiolitis is wider, including children with the first episode of wheeze before the age of two years. ${ }^{4}$

Many children will experience an episode of bronchiolitis or wheeze during their first year of life, with a possible increasing incidence as found by Carroll et al in the United States (19\% infants in $1996 / 97$ to $26 \%$ in $2002 / 03)^{5,6}$. Acute bronchiolitis is the most common cause of admission to hospital in infancy in many countries, including Norway ${ }^{7}$, with a strain on resources (economic and staff) in paediatric departments during the epidemics. In Norway, the mean annual hospitalization incidence for RSV bronchiolitis was reported to be $1.0 \%$ in 
the 1970 's $\mathrm{s}^{8}$ and $2.2 \%$ in 1990 's for children below 12 months ${ }^{9}$, which is similar to that in other Western countries s,3,10-12 $^{2}$

Some infants will have a severe course of bronchiolitis ${ }^{13}$. Bronchiolitis is the most common medical reason for admission of children to intensive care units (ICU), providing challenges regarding ventilation, fluid balance and general support ${ }^{14}$.

Children who have experienced an episode of acute bronchiolitis in infancy are at increased risk of asthma at all ages ${ }^{15-20}$, as observed in the 1980 's in Oslo where $60 \%$ of infants with acute bronchiolitis had suffered at least three episodes of wheeze by 2 years of age, ${ }^{21}$ diagnosed as asthma and in Sweden where $65 \%$ of infants had experienced a median of 4 (112) wheezing episodes 30 months after an RSV bronchiolitis. ${ }^{22}$ Whether this reflects a common cause of the two conditions or causality from acute bronchiolitis to later disease is still unclear. However, particularly two studies support at least a partial role of RSV in the pathogenesis of recurrent wheeze; A randomized controlled trial of palivizumab prophylaxis, a specific antibody against respiratory syncytial virus, reduced subsequent episodes of wheezing in premature infants ${ }^{23}$. A retrospective cohort study of 96000 children ${ }^{24}$ found that an age of four months of age at the peak of the first winter viral season was associated with both clinical bronchiolitis and childhood asthma - an association that followed the up to two months variation of viral peak between different years.

A relationship between acute bronchiolitis in infancy and clinical allergy and allergic sensitization up to early adulthood has been reported in the study by Sigurs et $\mathrm{al}^{17,25}$. There is a growing view that sensitization to allergens acts in synergy with viral respiratory 
infections to alter lung growth processes and drive the development of asthma ${ }^{26}$, particularly in relation to HRV infections leading to lower respiratory tract infections. ${ }^{27}$ 


\subsection{Treatment of acute bronchiolitis}

Treatment of acute bronchiolitis is generally supportive. Supplementary oxygen and nasogastric tube feeding are most commonly used. Ventilatory support, most commonly non-invasive continuous positive airway pressure (CPAP), is used in $5-10 \%$ of hospitalized patients. $^{28,29}$

The medications that have been attempted in acute bronchiolitis include, administered both systemically and through inhalations; antivirals, corticosteroids, teophyllamine, antibiotics, bronchodilators, leukotriene inhibitors and, most recently, inhaled hypertonic saline. Unfortunately, no treatment is proved to be effective in the outcomes that are regarded particularly important to patients and clinicians, such as the use of supportive care or LOS. ${ }^{30}$ Still, recent data from 38000 US hospitalizations showed that $58 \%$ receive bronchodilators, $16 \%$ steroids and $33 \%$ antibiotics ${ }^{31}$. Frequent and highly variable medication use has also been documented in other regions ${ }^{32-35}$.

The most common first line treatment for acute bronchiolitis in the last decades has been inhalations with adrenergic bronchodilators, either in the form of beta-2 specific agonists such as salbutamol or both alpha- and beta-adrenergic adrenaline ${ }^{36-38}$. A potential mucosal de-swelling effect ${ }^{39}$ of adrenaline, suggesting a benefit over $\beta$-2-agonists ${ }^{40}$, has led to frequent use of inhaled adrenaline ${ }^{41}$, particularly in Scandinavia and North America ${ }^{31,42}$. Some studies have shown a symptomatic improvement ${ }^{40,43-49}$ and reduced hospitalization rate for acute bronchiolitis in outpatients ${ }^{40}$. However, no benefit was observed in inpatients by length of hospital stay (LOS), after 1-3 inhalations ${ }^{49}$ or inhalations throughout the hospital stay in two studies, including 149 and 62 subjects respectively ${ }^{40,50,51}$. 
The international guidelines on bronchodilators for acute bronchiolitis have been conflicting. The SIGN guidelines (United Kingdom) have not recommended its use, while the American Academy of Pediatrics has recommended an individual trial with critical evaluation of effect $^{52,53}$. Inhaled adrenaline was the recommendation to all hospitalized patients with acute bronchiolitis in Norway until 2013, with a suggested treatment interval up to every hour. $^{54}$

Although side effects of inhaled adrenaline in general are reported as benign, usually tachycardia, discomfort and tremors ${ }^{4,55}$, fatal outcome due to wrong administration (intravenous) has been reported. The direct cost of adrenaline would most places be considered low, but the preparation of each weight-specific dose, administration of inhalation and assessment of the effect and side-effect are time consuming. Therefore, frequent administrations of inhalations to the numerous bronchiolitis patients during epidemics require significant nurse resources.

Inhaled nebulized solutions can be prescribed by fixed schedule or on demand, which allows clinical judgment of individual treatment response and optimize timing of inhalations, in line with the concept of minimal handling. ${ }^{56}$ We were unable to find documentation on the efficacy of these two strategies in children with acute bronchiolitis.

Prior to the present project, the status of bronchiolitis management was best summarized by the following statement of Smyth and Openshaw in their 2006 Lancet Seminar ${ }^{57}$ :

Surveys of clinical practice in the acute management of bronchiolitis from many centres across the world have shown wide variations, even within the same country. There is much controversy, confusion, and lack of evidence over the best treatments for this common, life-threatening condition. Clinical trials of interventions in 
bronchiolitis have been criticized for being too small and focusing on short-term outcomes, rather than reporting outcomes of interest to clinicians and parents, such as length of hospital stay.

The current knowledge at the time, as stated above, was the basis for the conception of the Bronchiolitis ALL-SE study. 


\subsection{Acute bronchiolitis and the role of airway viruses}

The first association of a specific virus to acute bronchiolitis in infants was published by Chanock et al in $1957^{25,58}$. The following year several studies described the virus and its mechanism of causing disease and gave it the name Respiratory syncytial virus ${ }^{58-62}$. For five decades now, RSV has been generally accepted to be the principal cause of severe lower respiratory tract infections in infants ${ }^{3,63,64}$, also in Norway. ${ }^{8,65,66}$

Respiratory syncytial virus causes seasonal outbreaks worldwide, in the winter in temperate climates and usually in the rainy season in tropical climates ${ }^{8,67-69}$.

Final identification of the virus could take up to 21-28 days with cell cultures, so it was not until a reliable, rapid immunofluorescence technique was published in 1968 that viral diagnostics became useful in daily clinical practice ${ }^{70}$.

Detection by immunofluorescence is still being used in some settings today, but has lost ground to ELISA (enzyme-linked immunosorbent assay) ) $^{71}$ and real-time polymerase chain reaction (PCR), first introduced with RSV in $1992^{72}$. Modern PCR methods have high sensitivity and specificity, and are usually applied as multiplex panels with the possibility to detect several respiratory viruses in one procedure. With this approach, in infants with acute bronchiolitis, RSV is detected in $60-90 \%$ of the cases ${ }^{3,63-65,73}$. Human rhinovirus (HRV) is the second most commonly detected virus (14-30 \%), followed by human bocavirus (HBov) (14$15 \%)$, human metapneumovirus (MPV) (3-12\%), entero-, adeno- (AdV), corona (CoV) and influenza viruses (1-8\%). ${ }^{74}$ Detection of two or more viruses in the same individual with acute bronchiolitis is reported in up to $20-30 \%$ of children ${ }^{5,63,64,74,75}$. 
Several attempts have been made to link subgroups of patients, based on the presence of different viruses, with severity of disease. The results have been conflicting as to whether the presence or absence of RSV ${ }^{76-80}$ or HRV, including subtypes ${ }^{81,82}$ is associated with clinically relevant outcomes of acute bronchiolitis like the length of hospital stay or need for oxygen, feeding/fluid or ventilatory support. Respiratory syncytial virus has been associated with increased disease severity in some ${ }^{76-78}$, but not all ${ }^{75,79}$ studies. Studies have shown higher $^{79}$, unchanged ${ }^{80}$ or lower ${ }^{76,82-84}$ disease severity in patients with a positive compared to a negative finding of HRV. The presence of the recently discovered ${ }^{85} \mathrm{HRV}$ type $\mathrm{C}$ strains has been associated with more severe obstructive airways disease in young children with an acute lower airway infection ${ }^{86,87}$. However, studies focusing on infants with bronchiolitis have been unclear on this association ${ }^{82,84}$.

Studies of viral load and disease severity in children with bronchiolitis have in general shown a positive relationship, as a higher concentration of RSV in nasopharyngeal aspirates has been associated with a more severe disease ${ }^{75,88-91}$.

The significance of coinfections is debated and may have major clinical impact on the guidelines for isolation of hospitalized patients. Studies have shown coinfection rates ranging from $9 \%$ to $41 \%$, with conflicting association with disease severity ${ }^{75,83,92}$. Brand et al ${ }^{75}$ examined 142 samples for 15 different viruses, found more than one virus in $41 \%$, but no association with disease severity. In contrast, Richard et al ${ }^{92}$ found in a study of 180 infants that children with co-infections (24\%) were 2.7 times more at risk for PICU admission than those with a single infection. A question that arises with high coinfection rates is whether or not concurrent detection of different viral genomes in the same nasopharyngeal aspirate 
represents simultaneous infections of clinical relevance, partly "left-overs" from previous infections, asymptomatic infections or a carrier/virome state.

Studies to assess if viral aetiology may modify treatment effect have been requested ${ }^{76}$, but not previously reported. 


\subsection{Allergic disease and treatment response in acute bronchiolitis}

Atopic diseases, including atopic eczema, allergies and asthma, are among the most frequent chronic disorders in childhood, and will be experienced by between 25 and $40 \%$ of the population in Norway and elsewhere.

The atopic diseases partly share pathophysiological mechanisms, hereditary risk factors and clinical phenotypes. Affected individuals often debut in the first year of life with atopic eczema, followed by food allergy, asthma and allergic rhinitis, a sequence of symptoms and signs known as the "atopic march"..$^{93}$ Numerous triggers may spark an allergic response, including aeroallergens such as pollen and animal danders, food allergens and irritants including tobacco smoke, aerosols, physical activity and cold air. However, recent studies indicate that the developmental path may not be a succession from one allergic manifestation to the next, but may rather be related to common early factors acting in concert. $^{26,94,95}$

During infancy, the immune and respiratory systems are undergoing developmental changes. The role of lower respiratory viral infections in this vulnerable period for the development of atopic conditions, perhaps through disturbance of the Th1/Th2 balance, is debated. Several observational studies have shown an increased risk of asthma in childhood and adolescence among individuals that have experienced an episode of moderate to severe lower respiratory tract in infancy, while the association with atopic eczema is less clear. $40,57,96,97$

Allergic diseases are often, but not always related to allergic sensitization, such as determined by skin prick tests or serum IgE-analyses. The relation between and timing of allergic sensitisation and asthma and atopic eczema is complex, ${ }^{98-100}$ and the relative 
contribution of s-IgE to allergic co-morbidities in 4 and 8-year old children from a large study including European of birth-cohorts, was recently shown to be less than $40 \% .{ }^{95}$ However, allergic sensitization may well be present without concurrent clinical symptoms of allergy, as illustrated by the presence of s-lgE to food allergens in children who tolerate the particular food. Although common among patients with atopic eczema and asthma, the role of allergic sensitization in the development of these diseases is unclear. A leading view today is that allergic sensitization alone rarely leads to asthma, but rather acts in synergy with environmental factors, most importantly viral infections, to drive disease development (Figure 1).

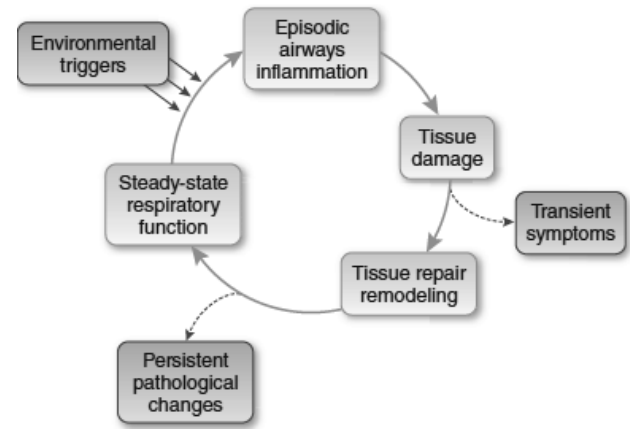

Figure 1: The inflammatory cycle in asthma pathogenesis. Asthma development is driven by repeated cycles of inflammation triggered by airborne irritant stimuli (top). From Nature Medicine, Holt PG and Sly PD. Viral infections and atopy in asthma pathogenesis: new rationales for asthma prevention and treatment, 18 (5), 726-735. Copyright (C) (2012) Nature Publishing Group. Reprinted with permission. ${ }^{26}$

The association between acute bronchiolitis

in infancy and subsequent development of pre-school asthma has most likely contributed to the extrapolation of asthma management guidelines to the management of infants with acute bronchiolitis; more than half of the US, Swedish and Finnish bronchiolitis patients receive inhaled bronchodilators ${ }^{31,42}$. There seems to be a widespread belief among clinicians that the therapy might be beneficial in a subgroup of patients with recurrent wheeze or atopic disease/allergy. This is exemplified in a implementation of a clinical practice guideline 
study by Mittal et al published in Pediatrics in 2014, ${ }^{101}$ where patients with a history of asthma, atopy or allergy were selected to receive inhaled bronchodilators.

The obvious challenge of this approach is the lack of precision between identifiable risk factors in infancy and later asthma and atopic disease. To our knowledge, analyses of the influence of later established diseases on treatment response of inhaled bronchodilators have not previously been reported. 


\section{Objective and specific aims of the thesis}

The treatment guidelines for acute bronchiolitis have varied throughout the world, particularly in regards to inhalations with adrenaline and other bronchodilators, with few sufficiently large studies of treatment effect in inpatients. Inhaled nebulized solutions can be prescribed for use on demand or on a fixed schedule. No studies have evaluated the comparative efficacy of these two strategies.

We therefore sought to test the hypothesis that inhaled racemic adrenaline is superior to inhaled saline in the treatment of acute bronchiolitis in infancy and that administration on a fixed schedule is superior to administration on demand. We also hypothesized that treatment response and disease severity may be influenced by viral etiology or allergic disease.

The specific research aims that emerged were:

1. Is inhaled racemic adrenaline effective in acute bronchiolitis in hospitalized infants? (paper \#1)

2. Is inhalation treatment "on demand" superior to "fixed schedule" in acute bronchiolitis in hospitalized infants? (paper \#1)

3. What is the role of airway viruses in acute bronchiolitis with respect to severity of disease and treatment response of inhaled adrenaline? (paper \#2)

4. What is the role of allergic disease, present at the time of the acute bronchiolitis or later, with respect to treatment response? (paper \#1,3) 


\section{Methods and subjects}

\subsection{Study design}

The study was performed in two phases;

1) Infants admitted to one of eight participating hospitals (Table 4) in south-eastern Norway from January 2010 through May 2011 with acute bronchiolitis were included to participate in a multicentre, double blind, randomized clinical trial. In accordance with a 2-by-2 factorial design, children were randomly assigned to receive inhaled racemic adrenaline or inhaled saline and to receive the assigned treatment on demand or on a fixed schedule (Figure 3). At inclusion, history of disease was registered, a clinical examination was performed and biological specimens were collected from the nasopharynx, blood, urine and saliva.

2) A follow-up investigation was conducted at two years of age, from September 2011 through December 2012, and included a parenteral interview, a clinical examination, a skin prick test (SPT) and collection of biological specimens as specified in figure 2.

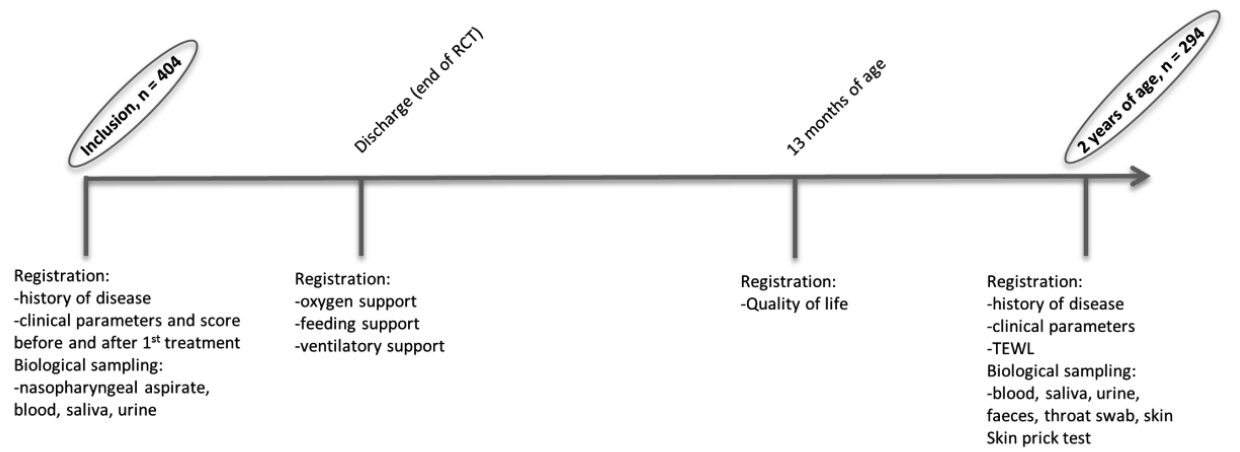

Figure 2: Study design timeline. RCT = Randomized Controlled Trial. TEWL: Trans-epidermal Water Loss. Assessment of Quality of Life is beyond the scope of this thesis. 


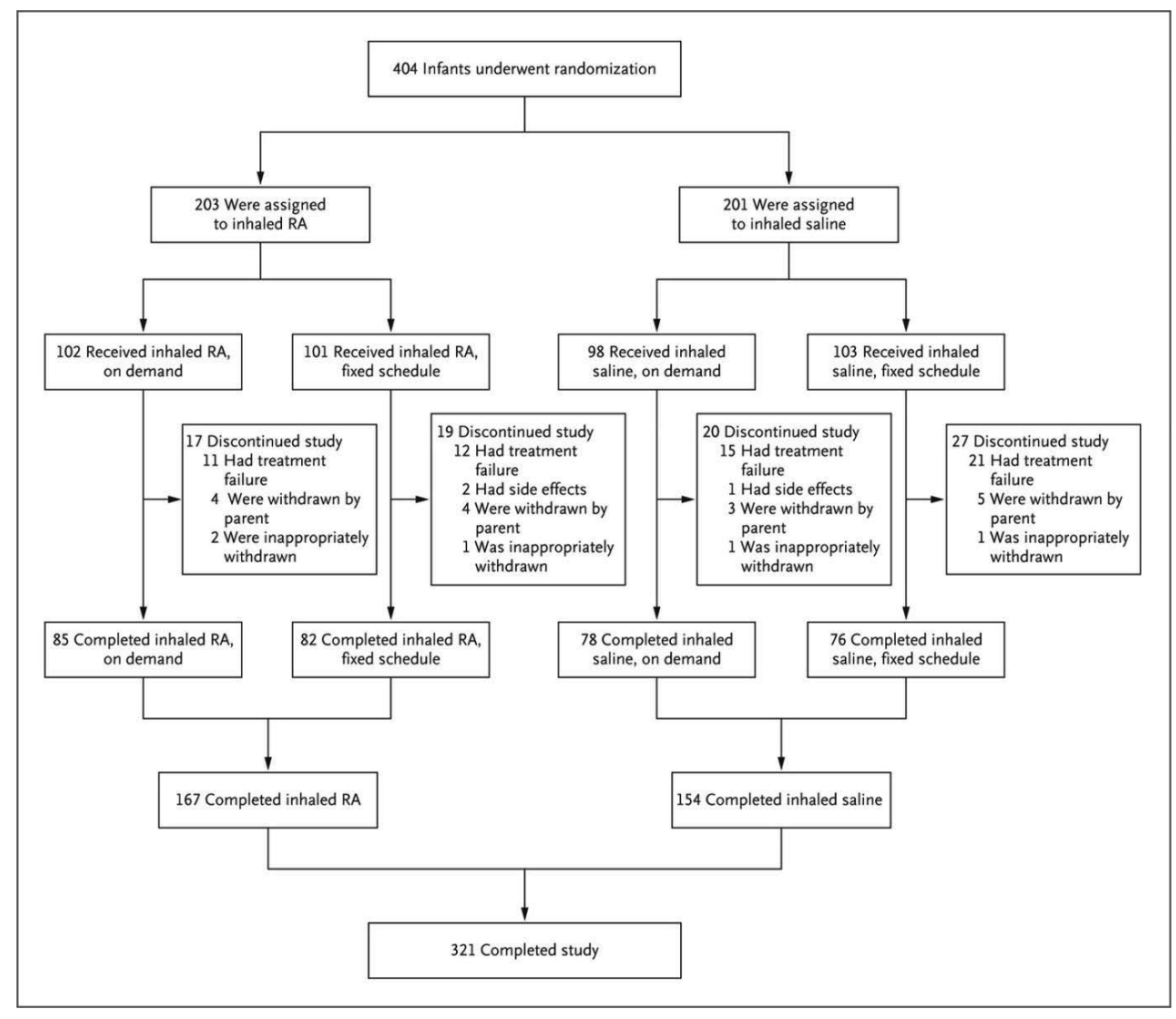

Figure 3: Randomization of the Study Patients. In five children, the study medication was discontinued because of the following administrative failures: administration of open inhaled racemic adrenaline (RA), suspected pertussis infection, delayed biologic sampling, administration of a dose of the study medication that was too high, and insufficient supply of study medication. From The New England Journal of Medicine, Skjerven HO, Hunderi JO, Brugmann-Pieper SK, et al. Racemic adrenaline and inhalation strategies in acute bronchiolitis, 368 (24), 2286-93. Copyright (c) (2013) Massachusetts Medical Society. Reprinted with permission. 


\subsection{Inclusion criteria and exclusion criteria}

\subsubsection{Inclusion criteria}

- Clinical signs of bronchiolitis, as defined by Court, (defined in the introduction, page $14)^{1}:$

- Age less than 12 months

- Clinical score of at least 4 on a scale of 0 to 10 . The clinical score was the sum of points allotted, from 0 (indicating normal findings) to 2 (indicating severe), for each of the following: general condition, skin colour, findings on auscultation, respiratory rate, and retractions (Table 1 ).

\begin{tabular}{|c|c|c|c|}
\hline & Score 0 & Score 1 & Score 2 \\
\hline $\begin{array}{l}\text { Respiratory rate } \\
\text { (breaths/min) }\end{array}$ & $<40$ & $40-60$ & $>60$ \\
\hline Respiratory chest recessions & None & $\begin{array}{l}\text { Moderate } \\
\text { Costodiaphragmatic }\end{array}$ & $\begin{array}{l}\text { Severe } \\
\text { As } 1,+ \text { rib and jugular } \\
\text { retraction }\end{array}$ \\
\hline $\begin{array}{l}\text { Auscultatory breath } \\
\text { sounds }\end{array}$ & Vesicular & Wheeze + rales/ronchi & $\begin{array}{l}\text { Faint } \pm \text { severe wheeze } \pm \\
\text { pronounced rales and ronchi }\end{array}$ \\
\hline Skin colour & Normal & Pallor & Cyanosis \\
\hline General condition & Not affected & Moderately affected & Severely affected \\
\hline
\end{tabular}




\subsubsection{Exclusion criteria}

- Any serious cardiac, immunologic, neurologic, or oncologic disease or pulmonary disease other than bronchiolitis.

- More than one previous episode of obstructive airway disease.

- Symptoms of disease of the lower airway (e.g., coughing) for more than 4 weeks.

- Receipt of any glucocorticoid therapy in the preceding 4 weeks.

\subsection{Methods phase 1}

\subsubsection{Recruitment and randomization}

Children were enrolled in the study on admission to the hospital whenever possible. A paediatrician performed clinical scoring. After written informed consent was obtained from one or both parent(s), children underwent randomization, and the assigned study medication was administered. The baseline characteristics of the children were obtained on admission, and the assessment included a paediatrician-guided, structured interview of one or both parents. Nasopharyngeal aspirates were sampled at inclusion, immediately frozen and analysed with the use of a polymerase-chain-reaction assay on common airway viruses in the University of Athens.

In a 2-by-2 factorial design, children were randomly assigned to receive inhaled racemic adrenaline or inhaled saline and to receive the assigned treatment on demand or on a fixed schedule (Figure 3). Randomization was performed centrally in blocks of eight, with assignment to one of the four study groups, with the use of SAS software, version 9.3. The randomization codes were communicated directly by the study statistician to the pharmacy, where doses of the two study medications $(10 \mathrm{ml}$ of racemic adrenaline dissolved in $0.9 \%$ 
saline to form a solution of $20 \mathrm{mg}$ per millilitre or $0.9 \%$ saline alone) were prepared in identical bottles, each labelled with a numerical code indicating the type of medication and timing of administration (on demand or fixed schedule). The study centres, which were not aware of the randomization block size, were provided with a list of study numbers for use in the consecutive assignment of medication to enrolled children.

The study physicians performing the clinical scoring were trained at investigator meetings as well as on site by the first author and by local primary investigators. 


\subsubsection{Study medication}

Doses of the two study medications $(10 \mathrm{ml}$ of racemic adrenaline dissolved in $0.9 \%$ saline to form a solution of $20 \mathrm{mg}$ per millilitre or $0.9 \%$ saline alone) were prepared in identical bottles, each labelled with a numerical code indicating the type of medication and timing of administration (on demand or fixed schedule). The study centres, which were not aware of the randomization block size, were provided with a list of study numbers for use in the consecutive assignment of medication to enrolled children.

The dose administered was based on the infant's weight: $0.10 \mathrm{ml}$ for infants weighing less than $5 \mathrm{~kg}, 0.15 \mathrm{ml}$ for those weighing 5 to $6.9 \mathrm{~kg}, 0.20 \mathrm{ml}$ for those weighing 7 to $9.9 \mathrm{~kg}$, and $0.25 \mathrm{ml}$ for those weighing $10 \mathrm{~kg}$ or more. The medications were diluted in $2 \mathrm{ml}$ of saline before nebulization and were administered through a Sidestream Reusable Nebulizer with a Respironics Facemask (both from Philips Respironics), driven by $100 \%$ oxygen at a rate of 6 litres per minute.

\subsubsection{Virus sampling and detection}

Nasopharyngeal aspirates were collected using a standardized procedure, performed by trained paediatric nurses at inclusion of the trial, with a tracheal suction set (Unomedical A/S, Lejre, Denmark), immediately frozen at $-20^{\circ} \mathrm{C}$ and transferred, without melting, to central storage in Oslo University Hospital $\left(-78^{\circ} \mathrm{C}\right)$ within four weeks. Each sample was melted and separated into two portions, one of which was transported on dry ice and batch analysed at the Allergy department of the University of Athens. Several of the participating hospitals, including in $80 \%$ of the patients at Oslo University Hospital, performed a second nasopharyngeal sampling and viral analyses by PCR and immunoassays as part of their local routines. 
Virus nucleic acids were isolated using the QIAamp Viral RNA Mini Kit (Qiagen, Limburg, Netherlands) and carrier RNA (Qiagen) for increased isolation yield of small sequences. Reverse transcriptase PCR (RT-PCR) was performed using SuperScript ${ }^{\circledR}$ II Reverse Transcriptase (Invitrogen, Life Technologies, Carlsbad, CA, USA) with a starting volume of $10 \mu \mathrm{l}$ of genetic material in a $20 \mu \mathrm{l}$ final reaction volume with default reaction conditions (Invitrogen).

Amplification of viral target sequences was performed using dual priming oligonucleotide (DPO) and real amplicon amplification (READ) technology (Magicplex RV Panel Real-time Test, Seegene, Eschborn, Germany) ${ }^{102}$. The assay allows the detection of Influenza A (FluA, including H5N1, H1N1) virus, Influenza B (FluB) virus, RSV virus A/B ,MPV, AdV B/C/E and some of A/D/F), CoV, 229E/NL63/OC43, HRV, A/B/C, HBoV 1/2/3/4 and Parainfluenza virus (PIV, 1/2/3/4). Positive HRV samples were subsequently subtyped for HRV A, B and C based on the published PCR-based assay by Wisdom et al. ${ }^{103}$ The assay includes three internal controls; a nucleic acid isolation and RT amplification control against the Human RNAse P sequence, and two virus detection controls (positive/negative). PCR reactions were performed in the Rotorgene Q 6plex Real-time PCR platform (Qiagen) and the results were analysed in the Seegene Viewer for Real-time instruments (Seegene).

A real-time PCR reaction was considered positive when the accumulation of fluorescent signal crosses the cycle threshold $(\mathrm{Ct})$, that is, the signal strength required for a detection to be identified. In the assay that we used, the cycle threshold for a virus should be crossed before the $20^{\text {th }}$ cycle of amplification, for a sample to be considered positive for this specific virus, as determined by the manufacturer. 
The protocol included two normalization steps:

i. Evaluation of the RNA isolation and RT-PCR efficiencies: 95\% of the RNA/RT-PCR control Cts followed normal distribution over a very small range of Cts (2-3 cycles). Samples with poor RNA isolation/ RT-PCR amplification efficiencies (high Cts) were selected and excluded from the analysis as outliers of the bench-protocol ( 21 samples) since they could heavily bias the clustering procedure;

ii. Normalization of virus-specific Cts against the EPC (extraction and PCR control - virus positive control): this normalization was the equation: delta $\mathrm{Ct}=\mathrm{Ct}_{\text {target }}-\mathrm{Ct}_{\mathrm{EPC}}$, thus defining the delta Ct which allows the comparison of same viral sequences between different samples. Samples with low delta Ct values represent PCR reactions with high genomic load for the specific target viral sequence and high delta Ct-values represents a low genomic load, accordingly. As the Ct-values represent very different actual number of microbes for the different virus types, semi-quantitative categorization into tertiles or quartiles is common. ${ }^{104}$ However, as the different viruses may show a variety of Ct-patterns, researcher-driven categorization may be arbitrary and introduce cut-offs that does not correspond correctly. We therefore chose a data-driven approach with the application of cluster analyses in order to improve classification of viral genomic load. (Figure 4) 

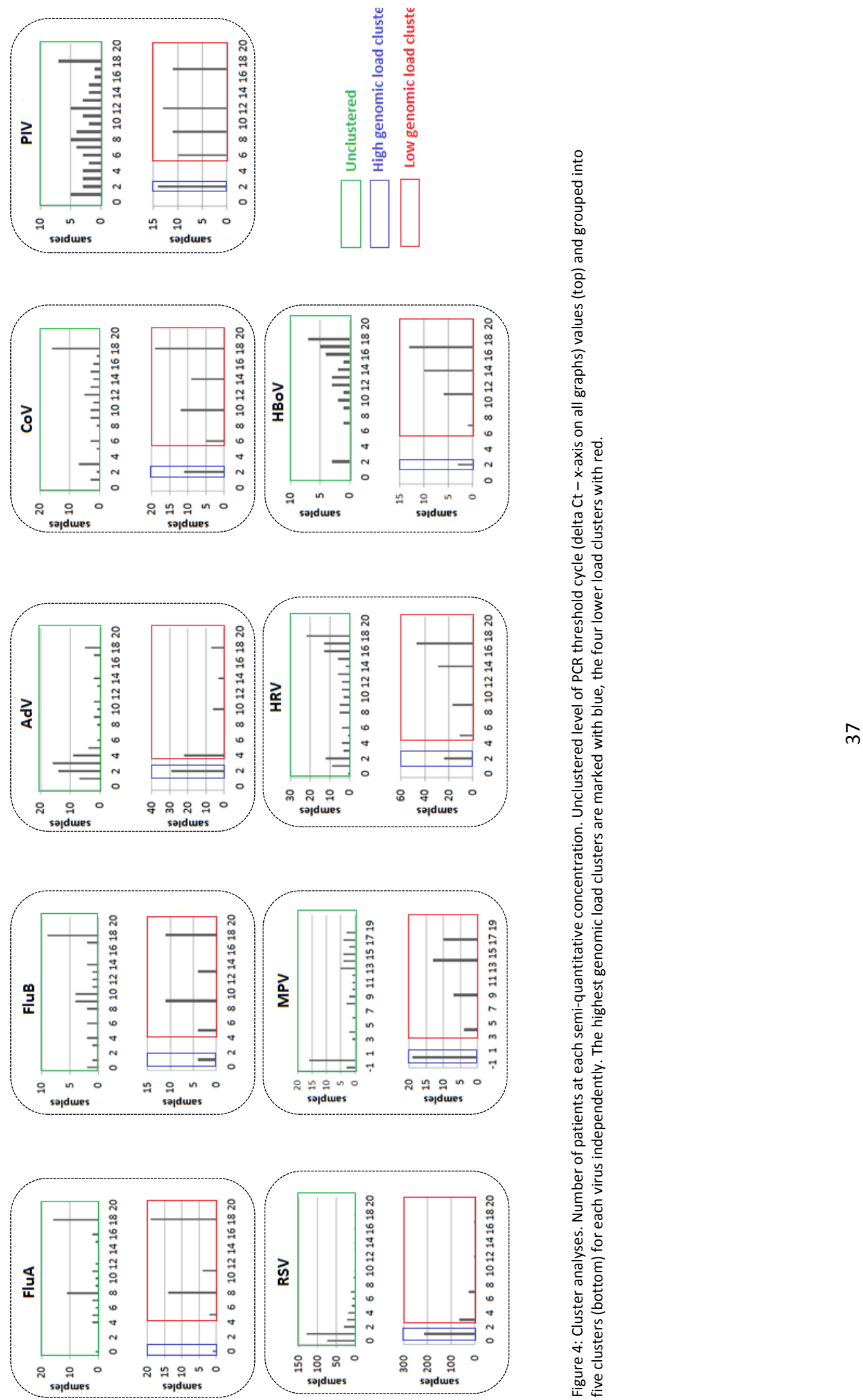


\subsection{Methods phase 2}

\subsubsection{Parental interview}

A specially trained physician, focusing on respiratory, allergy, and atopic eczema symptoms, did the structured interview of one or both of the patient's caregivers. Bronchial obstruction episodes were based on previous patient records and parental interview by physician, specified with the question: Has episodes of respiratory distress/wheezing occurred: yes/no. If yes: specify number of episodes during the first and second year of life.

\subsubsection{Clinical examination}

A study physician performed a general clinical examination and measured TEWL (transepidermal water loss - not further analysed in the present thesis). Scoring of respiratory distress and atopic eczema (SCORAD and Hanifin \& Rajka) were completed.

\subsubsection{Skin prick testing}

Skin prick testing was performed on the volar side of both lower arms with 11-17 relevant allergens (hen's egg white, peanut, almond, dog epithelium, cat epithelium, Dermatophagoides pteronyssinus, prawns, cow's milk, birch pollen, wheat, mug worth, timothy pollen, hazelnut, soy bean, cod, Cladosporium herbarum, and Alternaria tenius), and positive and negative controls. A skin reaction of $3 \mathrm{~mm}$ or more, after subtraction of the negative control, was defined as a positive test, and allergic sensitization was defined as a positive skin prick test to at least one allergen. 


\subsection{Outcome, definitions and explanatory variables}

\subsubsection{Treatment response}

Treatment response was primarily defined as change in the length of hospital stay, defined as the time from the first study inhalation until discharge from the hospital, as recorded in the medical record for each patient. Other outcomes of treatment response were change in the clinical score 30 minutes after the first inhalation and the use of supportive care in terms of nasogastric-tube feeding, oxygen supplementation and ventilatory support, all of which were recorded throughout the patient's hospital stay and reviewed in patient record.

\subsubsection{Modification of treatment response by virus}

The outcome for modification of treatment response was primarily assessed by the interaction between assigned randomization group (inhaled racemic adrenaline or saline) and the presence of (RSV, HRV or multiple viruses) on LOS.

\subsubsection{Level of supportive care}

The level of supportive care was categorized by Brand et al ${ }^{75}$ as 1 (no supportive care), 2 (use of oxygen and/or nasogastric tube feeding) or 3 (use of ventilatory support).

\subsubsection{Atopic eczema}

Atopic eczema was defined as either the presence of atopic eczema according to the criteria of Hanifin and Rajka requiring the presence of minimum three of four major criteria and minimum three of 23 minor criteria, ${ }^{105}$ or previously reported physician-diagnosed atopic eczema. 


\subsubsection{Recurrent bronchial obstruction}

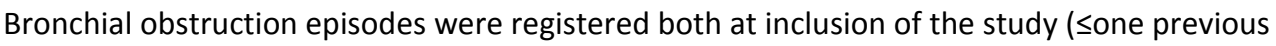
obstructive episode was allowed for inclusion) and at two years of age. Recurrent bronchial obstruction ( $\mathrm{rBO}$ ) was defined as the presence of at least three separate episodes of bronchial obstruction at any time, including the episode at the inclusion in the study, as defined on page 32 .

\subsubsection{Allergic sensitization}

A skin prick test wheal of $3 \mathrm{~mm}$ or more, after subtraction of the negative control, was defined as a positive test. Allergic sensitization was defined as a positive skin prick test to at least one allergen. 


\subsection{Statistical methods}

Continuous data are presented as means $( \pm S D)$, and categorical data are presented as numbers and percentages. Categorical data were assessed with the use of the Pearson chisquare test. Because data on length of stay had a non-normal distribution, comparisons between groups were assessed with the use of a robust, two-sample t-test and Huber's Mestimator, with $95 \%$ confidence intervals.

Interactions were assessed for inhaled racemic adrenaline versus inhaled saline and ondemand versus fixed-schedule administration, as well as for treatment and site, with the use of robust linear regression and Huber's M-estimator. The Jonckheere-Terpstra test was used to assess interactions between age (at 3-month intervals) and interventions. Local regression smoothing was applied to assess the effect of age on length of stay.

The power analysis was based on the length of stay of approximately 450 children hospitalized at the main study site during a 12-month period before the start of the study. Assuming that clinically relevant improvement would be indicated by a length of stay that was reduced by at least 5 hours in the group receiving inhaled racemic adrenaline ${ }^{106}$, we calculated that a total of 176 children in each medication group would provide a power of at least $80 \%$ at a two-sided alpha level of 0.05 . Owing to the inclusion of secondary outcomes and subgroup analyses, we increased the enrolment target to a total of 500 children.

Analysis of viral aetiology as an effect modifier of treatment was performed by interaction analyses in a robust linear regression model for the main outcome (length of stay).

To assess the effects in subgroups defined by clinical outcomes at age 2 years, we did interaction analyses between the predictors (recurrent bronchial obstruction, atopic eczema, 
and allergic sensitization) and the response of inhaled epinephrine versus saline on the outcomes (length of stay, with the use of robust linear regression and Huber's M-estimator; and the use of oxygen, nasogastric feeding, and ventilatory support with the use of logistic regression). Secondary survival analyses for potential differences in treatment effect related to clinical outcomes at 2 years of age were done by Cox regression on length of stay with interaction and stratified analyses. The length of stay by treatment is presented as KaplanMeier plots.

Stratified results of the difference in length of stay in subgroups are presented in a horizontal error bar plot. $p$ values of subgroup effects are presented, acknowledging the limitations of such $p$ values. ${ }^{107,108}$

All analyses are done by the intention to treat principle. The level of significance was set at 0.05 , and analyses were performed with the use of Stata software, version 13.1 and SAS software, version 9.3. 


\subsection{Ethical considerations}

The study was approved by the Regional Committees for Medical and Health Research Ethics and by the Norwegian Medicines Agency and is registered in the Norwegian Bio bank Registry. Written informed consent was obtained from a parent of each child before the start of therapy. The study was audited by the Norwegian Medicines Agency in 2011. The study was conducted in line with Good Clinical Practice. All patients were insured through the Drug Liability Association of Norway. 


\subsection{Subjects}

The study included 404 children (59.4\% of whom were boys) with a mean age of 126 days (4.2 months) upon enrolment. The 363 infants (90\%) with stored nasopharyngeal secretion available for further viral analyses were similar in baseline characteristics to the remaining $10 \%$, as listed in Table 2,

Recurrent bronchial obstruction, allergic sensitization and atopic eczema were assessed in the 294 children ( $73 \%$ of the 404 included in the $\mathrm{RCT}^{73}$ ) who completed the 2 years of age follow-up. The mean age of these children was 24.6 (95\% Cl 24.3-25.0) months at follow-up. $181(61.6 \%)$ of 294 patients were boys.

\begin{tabular}{lll}
\hline Characteristics & $\mathbf{R C T}(\mathbf{n}=\mathbf{4 0 4})$ & $\mathbf{2}$ year follow-up $(\mathbf{n}=\mathbf{2 9 4})$ \\
\hline Male sex . & $59.6 \%$ & $61.6 \%$ \\
Age, months $( \pm S D)$ & $4.2( \pm 2.9)$ & $24.6( \pm 3.3)$ \\
Father Caucasian & $92.1 \%$ & $92.5 \%$ \\
Mother Caucasian & $91.1 \%$ & $90.8 \%$ \\
Atopic eczema at inclusion & $10.7 \%$ & $10.7 \%$ \\
1 previous episode of bronchial & $22.7 \%$ & $26.5 \%$ \\
obstruction $(\%)$ at inclusion & & \\
Lower respiratory symptoms for $>1$ & $12.9 \%$ & $11.1 \%$ \\
week at inclusion & & \\
Parental asthma & $24.9 \%$ & $25.1 \%$ \\
Parental rhinoconjunctivitis & $31.7 \%$ & $32.6 \%$ \\
Clinical score ( $\pm S D)$ & $4.9( \pm 1.0)$ & $4.9(1.0)$ \\
SpO2 $( \pm S D)$ & $96.0( \pm 3.3)$ & $96.0(3.2)$ \\
Respiratory rate $( \pm S D)$ & $53.5( \pm 11.1)$ & $54.0(11.3)$ \\
Heart rate $( \pm S D)$ & $153.6( \pm 18.5)$ & $153.7(18.0)$ \\
\hline
\end{tabular}

Table 2: Baseline characteristics of patients participating in the RCT and the follow up study. 


\section{Results}

Baseline characteristics did not differ significantly among the four study groups (Table 3).

The study medication was discontinued in 83 children (20.5\%) for the reasons listed in Figure

3. The mean $( \pm S D)$ length of stay for all infants was $80 \pm 67$ hours; most children were

discharged between 8 a.m. and 11 p.m. (Fig. S1 in the Supplementary Appendix of Paper \#1).

\begin{tabular}{|c|c|c|c|c|}
\hline \multirow[t]{2}{*}{ Characteristics } & \multicolumn{2}{|c|}{ Inhaled Racemic Adrenaline } & \multicolumn{2}{|c|}{ Inhaled Saline } \\
\hline & $\begin{array}{l}\text { On Demand } \\
(\mathrm{N}=102)\end{array}$ & $\begin{array}{c}\text { Fixed } \\
\text { Schedule } \\
(N=101)\end{array}$ & $\begin{array}{l}\text { On Demand } \\
(\mathrm{N}=98)\end{array}$ & $\begin{array}{c}\text { Fixed } \\
\text { Schedule } \\
(N=103)\end{array}$ \\
\hline Male sex - no. (\%) & $63(61.8)$ & $60(59.4)$ & $54(55.1)$ & $63(61.2)$ \\
\hline Mean age - days & $134.9 \pm 91.6$ & $116.9 \pm 87.8$ & $117.8 \pm 68.1$ & $136.0 \pm 97.0$ \\
\hline \multicolumn{5}{|l|}{ Parental race - no./total no. $(\%) \uparrow$} \\
\hline Father white & $79 / 87(90.8)$ & $85 / 90(94.4)$ & $75 / 83(90.4)$ & $83 / 91(91.2)$ \\
\hline Mother white & $79 / 88(89.8)$ & $85 / 92(92.4)$ & $78 / 84(92.9)$ & $83 / 92(90.2)$ \\
\hline \multicolumn{5}{|l|}{ Medical history - no./total no. (\%) } \\
\hline Atopic eczema & $12 / 92(13.0)$ & $8 / 96(8.3)$ & $6 / 90(6.6)$ & $14 / 96(14.6)$ \\
\hline Allergies & $4 / 87(4.6)$ & $0 / 96(0)$ & $1 / 90(1.1)$ & $2 / 96(2.1)$ \\
\hline 1 previous wheeze & $24 / 88(27.3)$ & $23 / 91(25.3)$ & $20 / 90(22.2)$ & $31 / 93(33.3)$ \\
\hline Respiratory symptoms for $>1$ wk - no./total no. (\%) & $8 / 75(10.7)$ & $12 / 90(13.3)$ & $10 / 86(11.6)$ & $15 / 89(16.9)$ \\
\hline \multicolumn{5}{|l|}{ Parental medical history - no./total no. (\%) } \\
\hline Asthma & $17 / 78(21.8)$ & $22 / 83(26.5)$ & $23 / 80(28.8)$ & $21 / 84(25.0)$ \\
\hline Rhinoconjunctivitis & $23 / 88(26.1)$ & $33 / 89(37.1)$ & $23 / 87(26.4)$ & $34 / 92(37.0)$ \\
\hline \multicolumn{5}{|l|}{ Clinical characteristics before study inclusion } \\
\hline Clinical scoreł̣ & $4.9 \pm 1.0$ & $5.0 \pm 1.0$ & $4.9 \pm 1.0$ & $4.9 \pm 1.0$ \\
\hline $\mathrm{SpO}_{2} \mathrm{~J}$ & $96.0 \pm 3.6$ & $96.0 \pm 3.3$ & $96.0 \pm 3.4$ & $96.1 \pm 2.8$ \\
\hline Respiratory rate - breaths/min & $53.1 \pm 11.8$ & $53.6 \pm 10.5$ & $53.8 \pm 11.3$ & $53.4 \pm 11.1$ \\
\hline Heart rate - beats/min & $154.5 \pm 17.5$ & $156.0 \pm 18.7$ & $155.2 \pm 19.9$ & $153.7 \pm 17.7$ \\
\hline \multicolumn{5}{|c|}{ 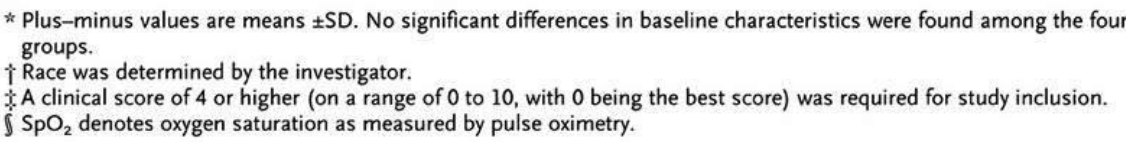 } \\
\hline
\end{tabular}

Table 3: Baseline characteristics of the study patients by randomization groups. . From The New England Journal of Medicine, Skjerven HO, Hunderi JO, Brugmann-Pieper SK, et al. Racemic adrenaline and inhalation strategies in acute bronchiolitis, 368 (24), 2286-93. Copyright @ (2013) Massachusetts Medical Society. Reprinted with permission. 
There was no interaction between the two treatment interventions (inhaled racemic adrenaline vs. inhaled saline and on-demand vs. fixed schedule), with an estimated interaction term of 1.4 hours (95\% confidence interval $[\mathrm{Cl}],-20.1$ to $22.8 ; \mathrm{P}=0.90$ ) (Table $\mathrm{S} 4$ in the Supplementary Appendix of paper \#1). This lack of interaction allowed for grouping inhalation strategy randomization groups together when evaluating medication type, and vice versa.

The number of children enrolled at each study centre ranged from 22 to 136 (mean, 51) (Table 4).

\begin{tabular}{ll}
\hline Hospital & $\mathbf{n}$ \\
\hline Oslo University Hospital & 136 \\
$\varnothing$ stfold Hospital HF & 100 \\
Vestre Viken Hospital HF & 28 \\
Vestfold Hospital HF & 38 \\
Sykehuset Innlandet Lillehammer HF & 23 \\
Sykehuset Innlandet Elverum HF & 28 \\
Sørlandet Sykehus HF & 22 \\
Sykehuset Telemark HF & 31 \\
\hline
\end{tabular}

Table 4: Number of patients per hospital 


\subsection{Is inhaled racemic adrenaline effective in acute bronchiolitis in}

\section{hospitalized infants? (paper \#1)}

There was no significant difference in length of hospital stay between children treated with inhaled racemic adrenaline and those treated with inhaled saline $(P=0.43)$ (Figure 5 and Table 5).

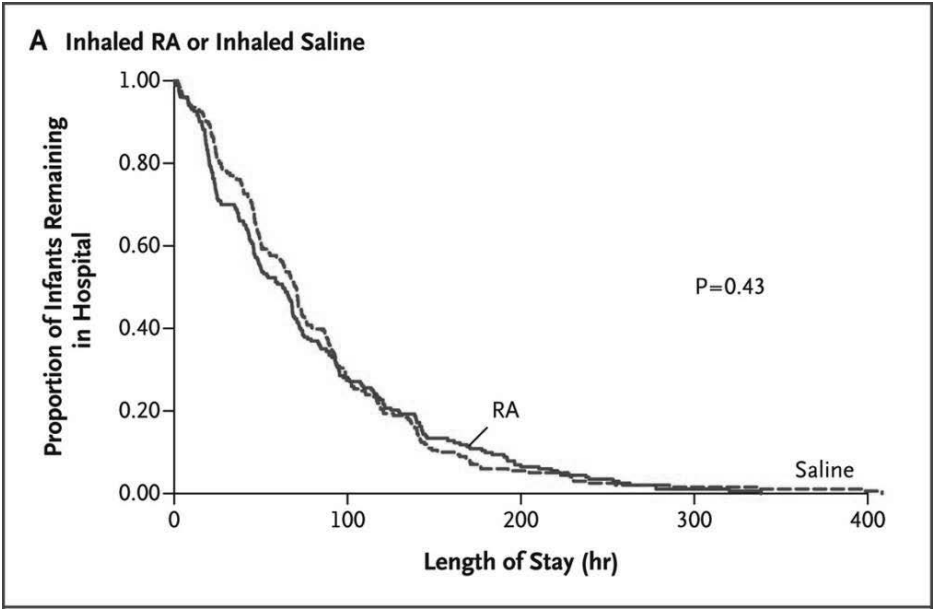

Figure 5: Length of hospital stay according to study treatment. . From The New England Journal of Medicine, Skjerven HO, Hunderi JO, Brugmann-Pieper SK, et al. Racemic adrenaline and inhalation strategies in acute bronchiolitis, 368 (24), 2286 93. Copyright (C) (2013) Massachusetts Medical Society. Reprinted with permission.

There were no significant between-group differences in the use of nasogastric-tube feeding, supplemental oxygen, or ventilatory support; clinical scores before and after the first inhalation of the study medication; or the number of children in whom the study medication was discontinued ( 36 children in the group receiving inhaled racemic adrenaline and 47 in the group receiving inhaled saline) (Table 5). 


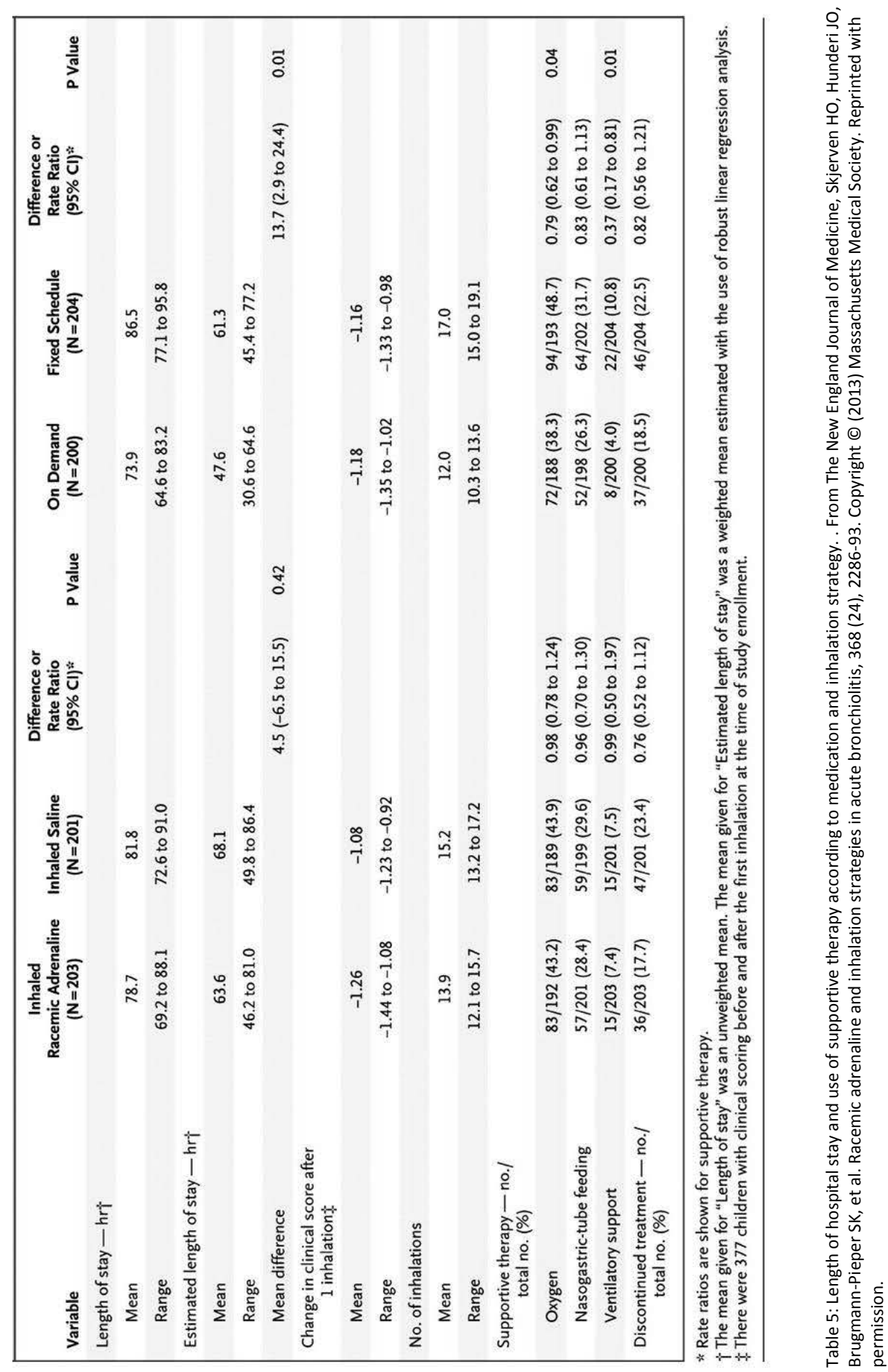




\subsubsection{The role of age}

Age (in 3-month periods) had a significant effect on length of hospital stay with regard to medication type, as estimated with the use of the Jonckheere-Terpstra test $(P<0.001)$.

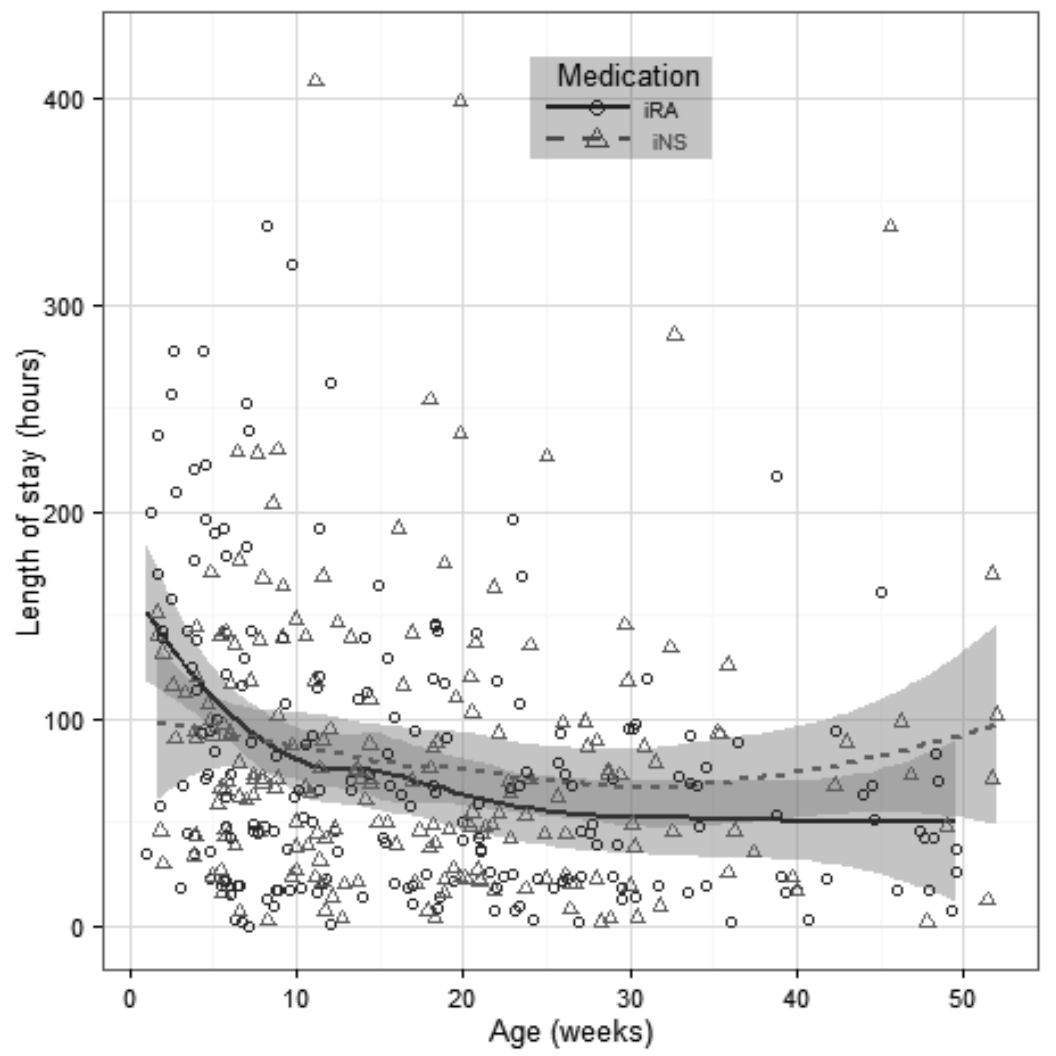

Figure 6: Length of Stay given by age for treatment medication with inhaled racemic adrenaline versus inhaled saline in infants with acute bronchiolitis. Regression lines are calculated by local regression smoothing, with $95 \%$ confidence interval shaded in gray for each of the smoothing lines. . From The New England Journal of Medicine, Skjerven HO, Hunderi JO, Brugmann-Pieper SK, et al. Racemic adrenaline and inhalation strategies in acute bronchiolitis, 368 (24), 2286-93. Copyright (C) (2013) Massachusetts Medical Society. Reprinted with permission.

The younger infants stayed longer in hospital than in the older infants in the group receiving inhaled racemic adrenaline compared to saline, as indicated with a curve showing the median at every time point (Figure 6). However, in subgroup analyses comparing children 
younger than 3 months of age (177, or $43.8 \%$ of the study population) with those 3 months of age or older, there was no significant difference between the effect of inhaled racemic adrenaline compared with that of inhaled saline.(Table 6)

\begin{tabular}{|c|c|c|c|c|}
\hline & Adrenaline & Saline & On demand & Fixed schedule \\
\hline \multicolumn{5}{|l|}{ Age $<3$ months } \\
\hline N & 92 & 85 & 86 & 91 \\
\hline Mean LOS, hours & 100.9 & 91.4 & 83.5 & 108.5 \\
\hline Estimated mean LOS*, hours $(95 \% \mathrm{Cl})$ & 93.1 & 89.2 & 41.3 & 71.6 \\
\hline $\begin{array}{l}\text { Mean difference in estimated mean LOS* } \\
\text { (95\% confidence interval) }\end{array}$ & \multicolumn{2}{|c|}{$-3.8(-24.7,17.0) p=0.72$} & \multicolumn{2}{|c|}{$30.3(10.3,50.3) p=0.003$} \\
\hline \multicolumn{5}{|l|}{ Age $>3$ months } \\
\hline N & 111 & 116 & 114 & 113 \\
\hline Mean LOS, hours & 60.2 & 74.8 & 66.7 & 68.7 \\
\hline Estimated mean LOS*, hours $(95 \% \mathrm{Cl})$ & 50.7 & 55.9 & 52.8 & 56.6 \\
\hline $\begin{array}{l}\text { Mean difference in estimated mean LOS* } \\
\text { (95\% confidence interval) }\end{array}$ & \multicolumn{2}{|c|}{$5.2(-6.7,17.0) p=0.39$} & \multicolumn{2}{|c|}{$3.8(-8.0,15.6) p=0.53$} \\
\hline
\end{tabular}

\subsubsection{Clinical responder analyses (Letter to the Editor)}

A positive clinical response from before to after the first inhalation was defined as an improvement in the clinical score of at least $25 \%$ or a higher category of oxygen saturation (<92\%, 92 to $95 \%$ or $>95 \%)$. We found a similar number of infants with a response in the adrenaline and saline groups (64\% in each group) and no significant difference in the length of hospital stay between infants who had a response and those who did not. 


\subsection{Is inhalation treatment "on demand" superior to "fixed schedule" in acute bronchiolitis in hospitalized infants? (paper \#1)}

The mean length of the hospital stay was significantly shorter for children in the group receiving treatment on demand than in the group receiving treatment on a fixed schedule $(\mathrm{P}=0.01)$ (Table 5 and Figure 7).

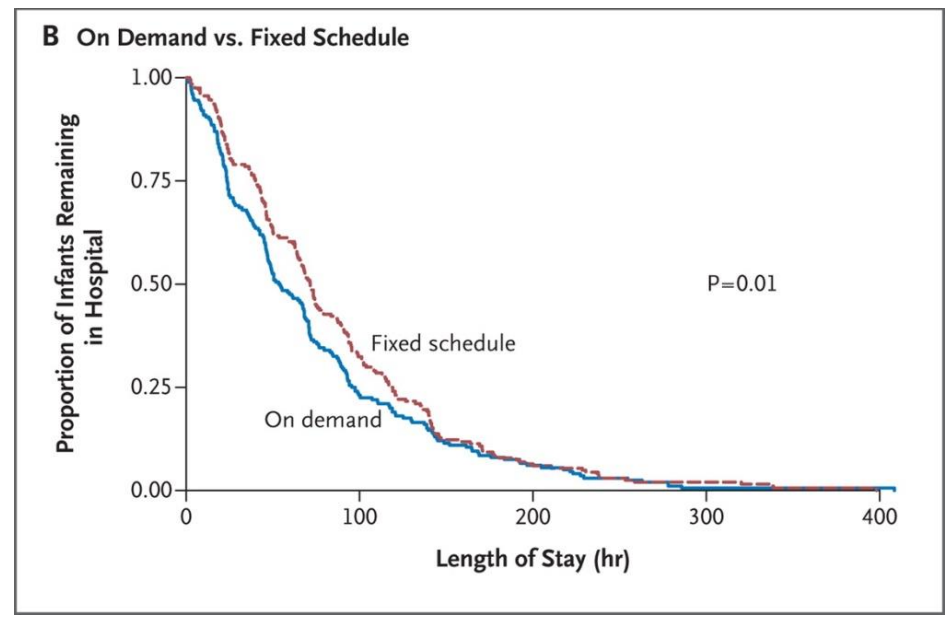

Figure 7: Length of hospital stay according to schedule of administration. From The New England Journal of Medicine, Skjerven HO, Hunderi JO, Brugmann-Pieper SK, et al. Racemic adrenaline and inhalation strategies in acute bronchiolitis, 368 (24), 2286-93. Copyright (C) (2013) Massachusetts Medical Society. Reprinted with permission.

Children in the on-demand group received a mean of 5.0 (30\%) fewer inhalations than those in the fixed-schedule group $(P<0.001)$. Children receiving inhalations on demand also had a lower probability of being treated with ventilatory support $(\mathrm{P}=0.01)$ or supplemental oxygen $(P=0.04)$. Inhalations given on demand were not significantly associated with nasogastrictube feeding or treatment discontinuation (Table 5). 


\subsubsection{The role of age}

Age (in 3-month periods) had a significant effect on length of hospital stay with regard to inhalation strategy, as estimated with the use of the Jonckheere-Terpstra test $(P<0.001)$.

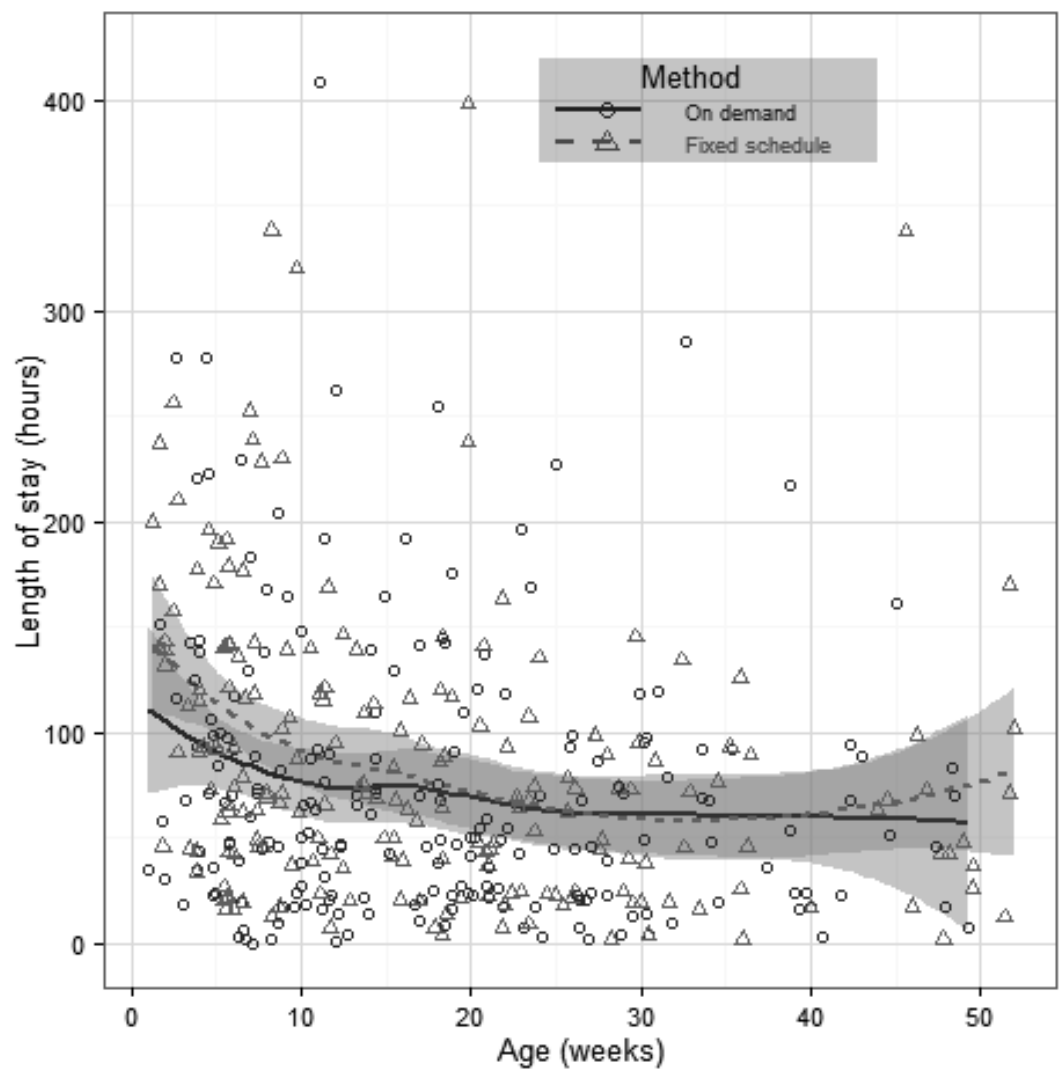

Figure 8: Length of Stay given by age for treatment strategy on demand versus fixed schedule in infants with acute bronchiolitis. Regression lines are calculated by local regression smoothing, with $95 \%$ confidence interval shaded in gray for each of the smoothing lines. . From The New England Journal of Medicine, Skjerven HO, Hunderi JO, Brugmann-Pieper SK, et al. Racemic adrenaline and inhalation strategies in acute bronchiolitis, 368 (24), 2286-93. Copyright ( $(2013)$ Massachusetts Medical Society. Reprinted with permission.

In subgroup analyses comparing children younger than 3 months of age $(177$, or $43.8 \%$ of the study population) with those 3 months of age or older, inhalations given on demand were associated with a significantly shorter hospital stay than were inhalations given on a fixed schedule (Table 6 and Figure 8). 


\subsection{What is the role of airway viruses in acute bronchiolitis with respect to severity of disease and treatment response of inhaled adrenaline?}

\section{(paper \#2)}

One or more viruses were detected in $91 \%$ of the patients, with RSV $(83 \%)$ and HRV $(34 \%)$ as the most common. Infants with RSV monoinfection were significantly younger, and infants infected with HRV monoinfection were significantly older, than infants with other detected viruses (Table E2 in the online supplement to paper \#2). Other airway viruses were detected at lower frequencies, ranging from the identification of influenza B in $8 \%$ of the population to adenovirus and coronavirus, each identified in 15\% of study subjects (Figure 9 and table E1 in the online supplement to paper \#2).

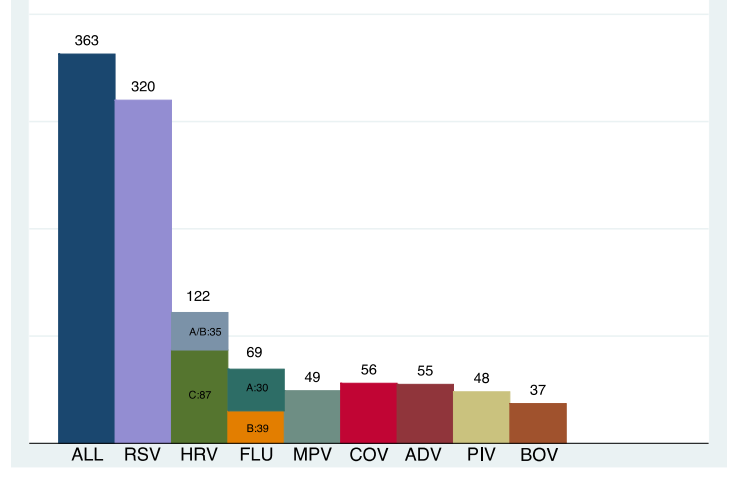

Figure 9: Number of patients with each virus 
RSV was present in $82 \%(89 / 108)$ of the patients with only one virus detected (Figure 10).

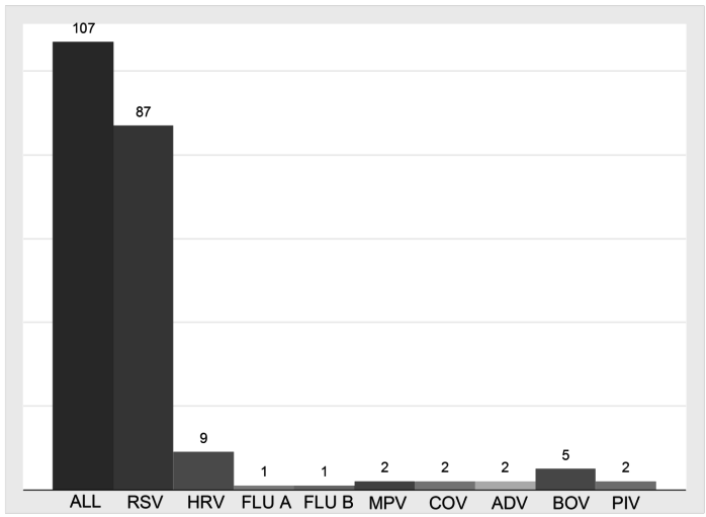

Figure 10: Monoinfections

Two or more viruses were detected in $61 \%$, three or more viruses in $30 \%$, and up to seven viruses were simultaneously detected (Figure 11).

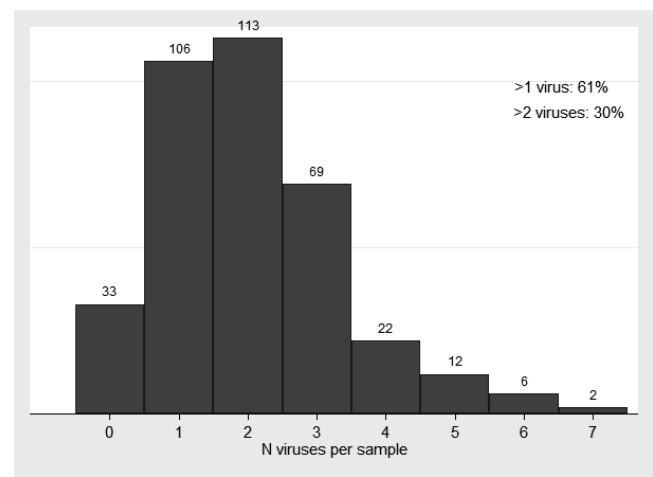

Figure 11: Frequencies of patients by simultaneously detected number of viruses. 
To address if viral load was associated with severity of disease or treatment effect, we reanalysed the dataset with classifying only the highest genomic load (highest cluster, see Figure 4) as a positive test for each virus. High genomic viral load of any virus was found in $70 \%$ of the patients; RSV in $55 \%, \mathrm{HRV}$ in $6 \%$ and other viruses in $1-12 \%$ of the cases (Table E2, online supplement to paper \#2). Coinfection was present in $18 \%$, three or more viruses in $3 \%$ and up to four viruses $(n=1)$ were simultaneously detected. RSV was present in $81 \%(36 / 188)$ of the patients with one virus detected only. 


\subsubsection{Virus presence and severity of disease}

Neither length of stay nor the level of supportive care was associated with the presence of RSV, HRV A/B, HRV C, influenza A, influenza $B$, parainfluenzavirus, adenovirus or bocavirus (Table E1, supplementary data to paper \#2 and Figure 12). Although length of stay was significantly longer in the presence of coronavirus $(17.1$ hours $(95 \%$ confidence interval $(\mathrm{Cl})$ 1.2 to 33.0 hours, $p=0.04$ ), and shorter with the detection of human metapneumovirus (19.3 hours $(\mathrm{Cl}-36.0$ to $-2.5, \mathrm{p}=0.02)$ ) (Figure 12$)$, the results were no longer statistically significant after adjusting for multiple testing.

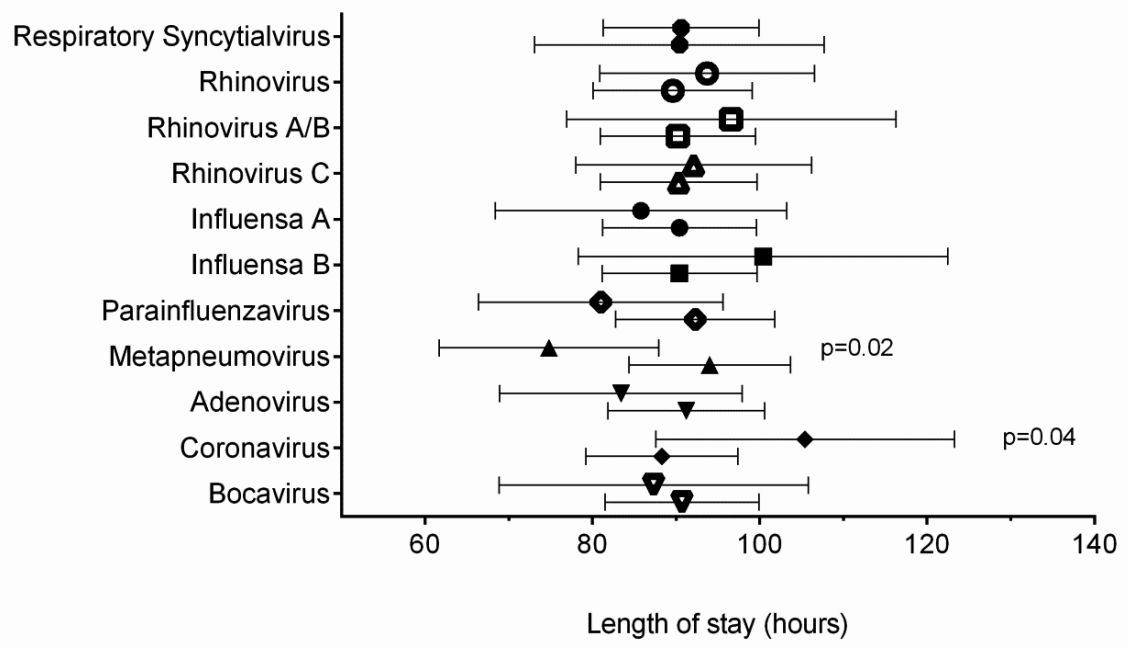

Figure 12: Pairwise comparisons are shown for a positive (top) versus a negative (corresponding below) PCR for each virus. The estimated mean length of stay was adjusted for age in a robust linear regression model. The associations between type of virus and length of stay were no longer statistically significant after adjustment for multiple comparisons.

However, the presence of RSV in high concentration was associated with the severity of disease in terms of longer LOS and higher level of supportive care (significantly more use of oxygen and ventilatory support) (Table E2, supplementary data to paper \#2). No other virus in high concentration was associated with the severity of disease. 
No significant associations with disease severity were found for coinfections, the specific combination of HRV and RSV or mono-infections (Table E1, supplementary data to paper \#2, Figure 13). However, in analyses with high genomic load, mono-infection of RSV was associated with an increased level of supportive care (Table E2, supplementary data to paper $\# 2)$.

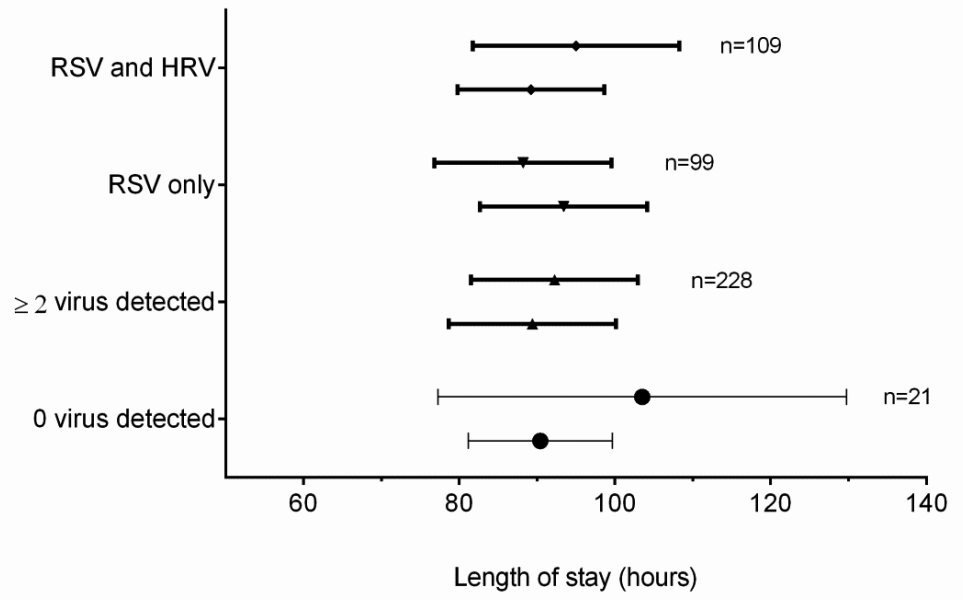

Figure 13: Pairwise comparisons are shown for a positive (top) versus a negative (corresponding below) PCR for viral subgroups. The estimated mean length of stay was adjusted for age in a robust linear regression model. There were no statistically significant associations between viral subgroup and length of stay. 


\subsubsection{Virus and treatment response of inhaled adrenaline}

The presence of more than one virus did not modify the effect of inhaled adrenaline versus saline on length of stay (all $p>0.5$ by interaction analyses). Stratified subgroup analyses are shown in Figure 14.

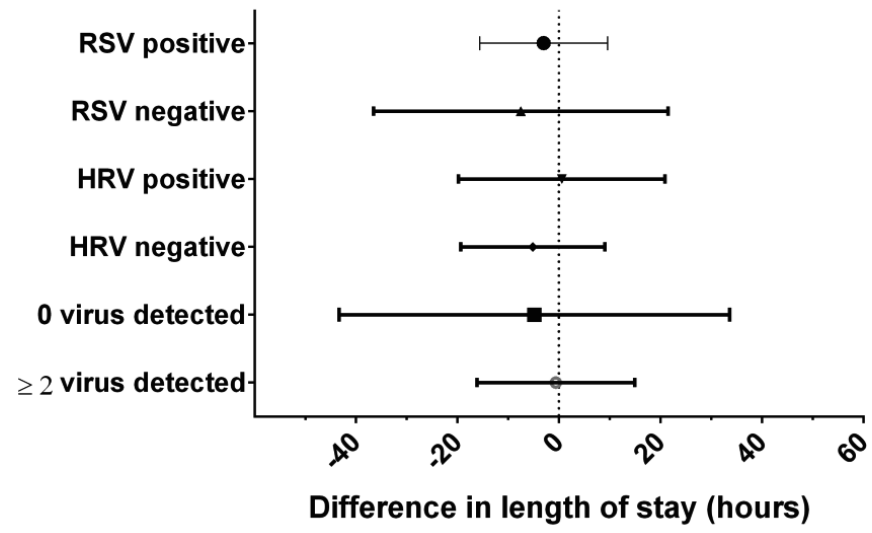

Figure 14: The effect of inhaled racemic adrenaline compared to saline on the mean length of stay (estimated in robust linear regression analyses) in subgroups by viral diagnostics.

The presence of RSV, HRV or coinfection of viruses in high genomic load did not significantly modify the effect of inhaled adrenaline on the length of stay (all $p>0.2$ by interaction analyses). 


\subsection{What is the role of allergic disease, present at the time of the acute bronchiolitis or later, with respect to treatment response? (paper \#1,3)}

Among the 295 infants who attended the 2-year follow-up investigation, mean length of hospital stay was 80.3 hours $(95 \% \mathrm{Cl} 72.8-87.9)$, similar to the 80.7 hours in all 404 infants. Baseline characteristics were comparable in the patients that attended and did not attend the follow-up study (Table 7) and in the treatment groups (Table 8). Baseline characteristics and length of hospital stay were similar in the four groups related to recurrent bronchial obstruction and atopic eczema or allergic sensitization at follow-up at age 2 years (Table 8 ).

$181(61.6 \%)$ of 294 patients were boys.

\begin{tabular}{|c|c|c|}
\hline Characteristics & $\begin{array}{l}\text { Attended follow- } \\
\text { up }(n=294)\end{array}$ & Lost to follow-up ( $n=110)$ \\
\hline Males & $181(61 \cdot 6 \%)$ & $59(53 \cdot 6 \%)$ \\
\hline Age, days & $124(85)$ & $134(95)$ \\
\hline Father, white & $272(92 \cdot 5 \%)$ & $100(90 \cdot 9 \%)$ \\
\hline Mother, white & $267(90 \cdot 8 \%)$ & $101(91 \cdot 7 \%)$ \\
\hline Atopic eczema & $29 / 271(10 \cdot 7 \%)$ & $11 / 103(10 \cdot 7 \%)$ \\
\hline $\begin{array}{l}\text { One previous episode of bronchial } \\
\text { obstruction }\end{array}$ & $69 / 260(26 \cdot 5 \%)$ & $29 / 102(28.4 \%)$ \\
\hline $\begin{array}{l}\text { More than } 1 \text { week of persistent } \\
\text { respiratory symptoms }\end{array}$ & $34 / 249(13 \cdot 7 \%)$ & $11 / 99(11 \cdot 1 \%)$ \\
\hline Parental asthma & $59 / 235(25 \cdot 1 \%)$ & $22 / 90(26 \cdot 7 \%)$ \\
\hline Parental rhinoconjunctivitis & $84 / 258(32 \cdot 6 \%)$ & $29 / 98(29 \cdot 6 \%)$ \\
\hline Clinical score & $4.9(1.0)$ & $4.9(0.9)$ \\
\hline $\mathrm{SpO}_{2}(\%)$ & $96 \cdot 0 \%(3 \cdot 2)$ & $96 \cdot 0 \%(3 \cdot 4)$ \\
\hline Respiratory rate (breaths per min) & $54 \cdot 0(11 \cdot 3)$ & $51.9(10 \cdot 4)$ \\
\hline Heart rate (beats per min) & $153 \cdot 7(18 \cdot 0)$ & $153 \cdot 5(19 \cdot 6)$ \\
\hline
\end{tabular}




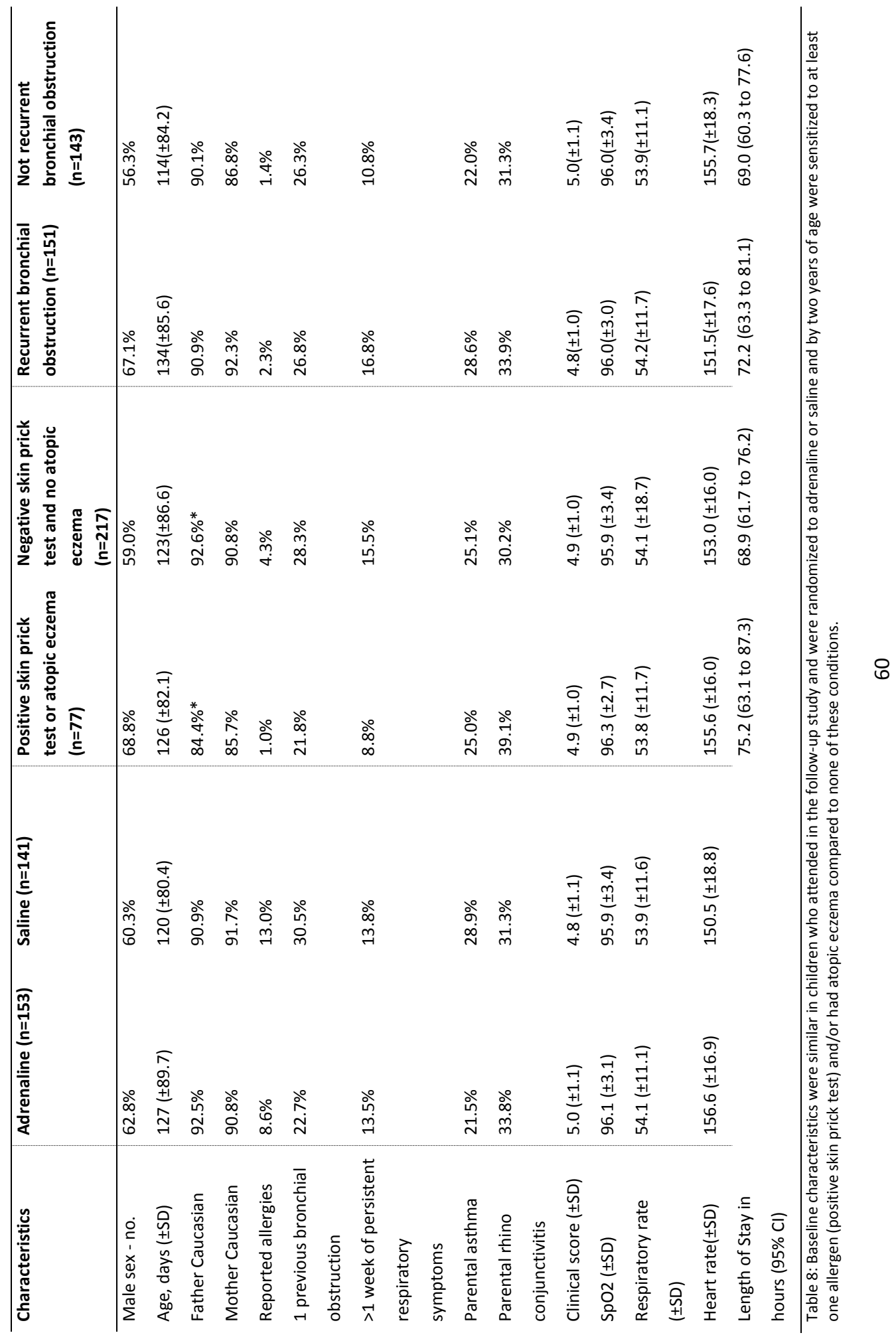




\subsubsection{Atopic eczema, previous episode of bronchial obstruction or family history of atopy on study enrolment}

Based on data registered at the time of the acute bronchiolitis in infancy, status with respect to a history of atopic eczema or previous lower airway obstruction (Table 9) or status with respect to a family history of atopic disease were not found to have a significant influence on treatment response.

\begin{tabular}{|c|c|c|c|c|}
\hline & Adrenaline & Saline & On demand & Fixed schedule \\
\hline \multicolumn{5}{|l|}{1 previous obstructive episode } \\
\hline $\mathrm{N}$ & 47 & 51 & 44 & 54 \\
\hline Mean LOS, hours & 78.1 & 88.6 & 85.0 & 82.4 \\
\hline Estimated mean LOS*, hours $(95 \% \mathrm{Cl})$ & 74.2 & 72.0 & 60.8 & 66.4 \\
\hline $\begin{array}{l}\text { Mean difference in estimated mean LOS* } \\
\text { ( } 95 \% \text { confidence interval) }\end{array}$ & \multicolumn{2}{|c|}{$-2.2(-26.8,22.3) p=0.86$} & \multicolumn{2}{|c|}{$5.6(-18.8,30.0) p=0.65$} \\
\hline \multicolumn{5}{|l|}{ No previous obstructive episode } \\
\hline $\mathrm{N}$ & 132 & 132 & 134 & 130 \\
\hline Mean LOS, hours & 81.7 & 81.2 & 72.9 & 90.3 \\
\hline Estimated mean LOS*, hours $(95 \% \mathrm{Cl})$ & 56.3 & 64.5 & 47.6 & 62.5 \\
\hline $\begin{array}{l}\text { Mean difference in estimated mean LOS* } \\
\text { (95\% confidence interval) }\end{array}$ & \multicolumn{2}{|c|}{$8.3(-4.8,21.3) p=0.22$} & \multicolumn{2}{|c|}{$14.9(1.81,28.0) \mathbf{p}=0.03$} \\
\hline
\end{tabular}

Table 9: Length of stay in subgroup by previous obstructive episode 


\subsubsection{Recurrent bronchial obstruction at two years of age}

Length of stay (Figure 15 and

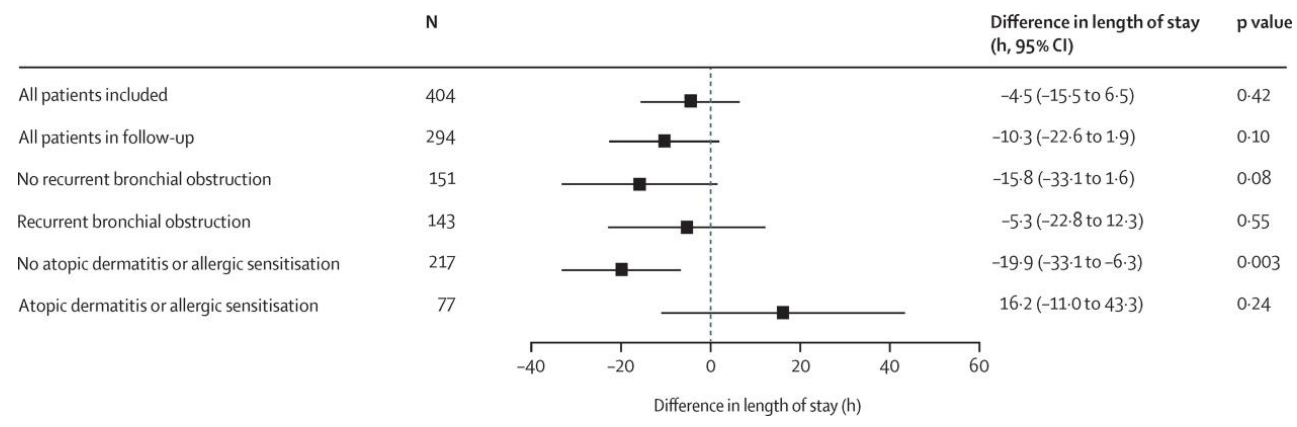

Figure 16) was not significantly modified by treatment with inhaled epinephrine versus saline in the subgroup of infants who developed recurrent bronchial obstruction by the age of two years (143 [48.6\%] of 294; pinteraction=0.40). The use of oxygen, nasogastric tube feeding, or ventilatory support also did not differ (all pinteraction $>0.1$ ). In stratified analyses of patients without recurrent bronchial obstruction by the age of two years, the difference in length of stay if receiving inhaled epinephrine versus saline was $-15.8 \mathrm{~h}(95 \% \mathrm{Cl}-33.1$ to 1.6 ; $p=0.08)$. In children with recurrent bronchial obstruction, the difference in length of stay was $-5.3 \mathrm{~h}(95 \% \mathrm{Cl}-22.8$ to $12.3 ; \mathrm{p}=0.55)$.
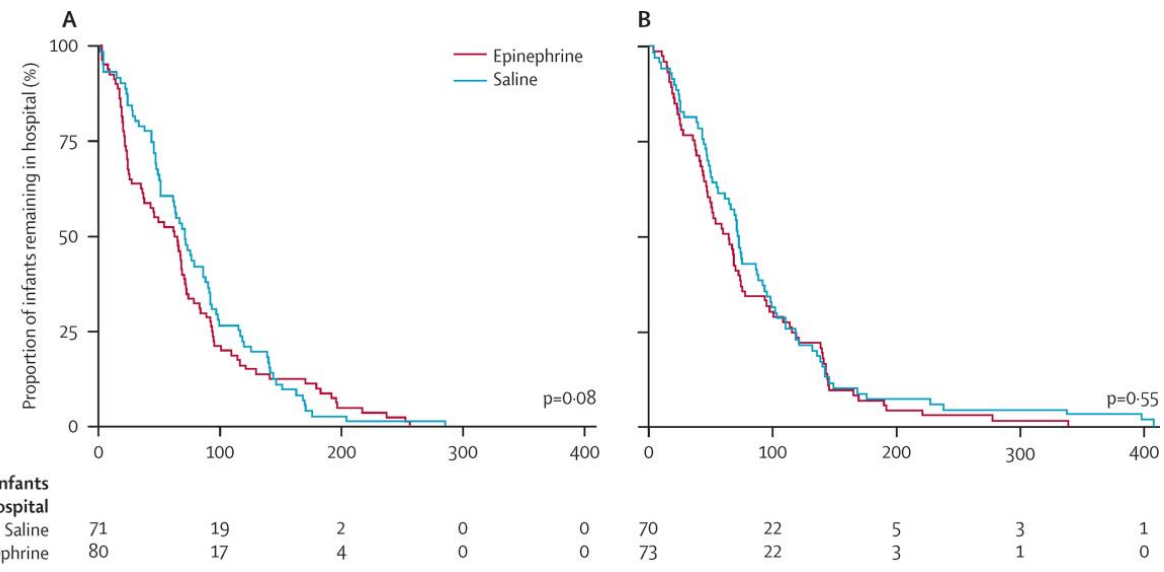
Figure 15: Length of hospital stay according to study treatment. Kaplan-Meier plots show the proportion of infants remaining in hospital according to whether they were treated with inhaled racemic epinephrine or inhaled saline in patients at the age of 2 years: (A) without recurrent bronchial obstruction (after secondary survival analysis: hazard ratio [HR] 1.13, 95\% Cl 0.82-1.57; $p=0.45)$; (B) with recurrent bronchial obstruction (HR 1.15, 0.83-1.61; $p=0.39$ ); $p$ values are from robust linear regression analyses. From The Lancet Respiratory Medicine, Skjerven HO, Rolfsjord LB, Berents TL, et al. Allergic diseases and the effect of inhaled epinephrine in children with acute bronchiolitis: follow-up from the randomized, controlled, double-blind, Bronchiolitis ALL trial 3 (9), 702-708. Copyright (C) (2015) Elsevier Limited. Reprinted with permission.

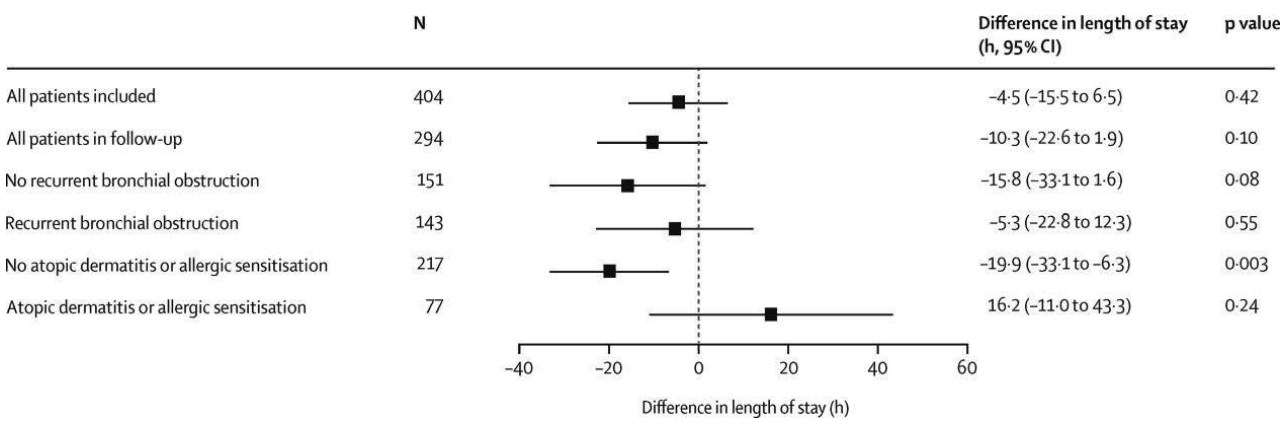

Figure 16: Treatment response to inhaled racemic epinephrine versus saline in infants with acute bronchiolitis, shown as difference in length of stay in hospital in subgroups based on the presence of recurrent bronchial obstruction, atopic eczema, or allergic sensitization by the age of 2 years. Error bars are $95 \% \mathrm{Cls}$ for the difference in estimated length of stay between patients who received inhaled epinephrine versus saline analyzed by robust linear regression. From The Lancet Respiratory Medicine, Skjerven HO, Rolfsjord LB, Berents TL, et al. Allergic diseases and the effect of inhaled epinephrine in children with acute bronchiolitis: follow-up from the randomized, controlled, double-blind, Bronchiolitis ALL trial 3 (9), $702-$ 708. Copyright @ (2015) Elsevier Limited. Reprinted with permission.

Recurrent bronchial obstruction did not significantly modify the response to the first

inhalation of epinephrine measured by change in clinical score $\left(p_{\text {interaction }}=0.24\right)$.

There was no interaction between inhalant strategy (on-demand versus fixed schedule) and

recurrent bronchial obstruction $\left(p_{\text {interaction }}=0.29\right)$ on the length of stay. Stratified analyses are

presented in the appendix to paper\#3. 


\subsubsection{Atopic eczema and allergic sensitization at two years of age}

By 2 years of age, atopic eczema was diagnosed in 68 (23.1\%) of 294 children, either previously by a doctor $\left(n=48\right.$ ) or by meeting Hanifin and Rajka's criteria ${ }^{105}$ at the follow-up investigation $(n=38)$. Allergic sensitization (positive skin prick test) was present in $23(8.0 \%)$ of 287 (7 did not perform SPT) individuals (allergens: peanut, $n=9$ [3.1\%]; cat, $n=7$ [2.4\%]; egg, $\mathrm{n}=5$ [1.7\%]; almond, $\mathrm{n}=4$ [1.4\%]; dog, $\mathrm{n}=4$ [1.4\%]; D pteronyssinus, $\mathrm{n}=1$ [0.4\%]; prawn, $\mathrm{n}=1$ [0.4\%]; and cow's milk, $\mathrm{n}=1[0.4 \%])$.

The presence of atopic eczema or allergic sensitization by the age of 2 years $(n=77)$ significantly interacted with the treatment effect of inhaled epinephrine in terms of length of hospital stay when analysed by robust linear regression analyses $\left(p_{\text {interaction }}=0.02\right.$ ) and by Cox regression analyses $\left(p_{\text {interaction }}=0.03\right)$, and the use of supplementary oxygen $\left(p_{\text {interaction }}=0.03\right)$. In patients without atopic eczema or allergic sensitization by the age of 2 years ( $n=217 / 294$, 73.8\%), inhaled epinephrine significantly reduced length of stay versus saline $(-19.9$ h, $95 \%$ $\mathrm{Cl}-33.1$ to $-6.3 ; \mathrm{p}=0.003)$ but did not affect the need for additional oxygen support $(46 / 106$, $43.4 \%$ versus $54 / 103,52.4 \%$; rate ratio 0.83 [0.62 to 1.10 ]; $p=0.19$ ). In patients with atopic eczema or allergic sensitization ( $n=77 / 294,26.2 \%$ ) there was no statistically significant effect of inhaled epinephrine versus saline on length of stay $(+16.2 \mathrm{~h}, 95 \% \mathrm{Cl}-11.0$ to $43.3 ; \mathrm{p}=0.24$; Figure 2 and Figure 3) or on the need for additional oxygen support (17/40, 42.5\% versus 7/31, 22.6\%; rate ratio 1.88 [95\% Cl 0.89-3.96]; $p=0.09$ ). Secondary stratified survival analyses showed that children who received inhaled epinephrine without atopic eczema or allergic sensitization had a hazard ratio (HR) of 1.38 (95\% $\mathrm{Cl} 1.05-1.81 ; \mathrm{p}=0.02)$ for being discharged from hospital, compared with $0.77(0.48-1.22 ; p=0.26)$ for being discharged from hospital for children with atopic eczema or allergic sensitization. 

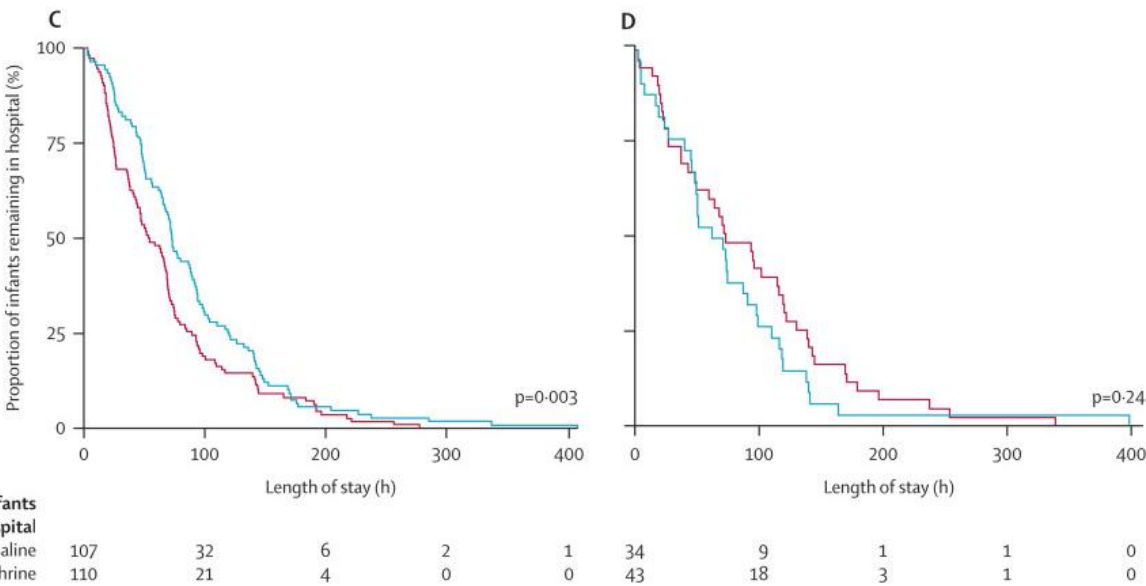

Figure 17: Length of hospital stay according to study treatment. Kaplan-Meier plots show the proportion of infants remaining in hospital according to whether they were treated with inhaled racemic epinephrine (blue) or inhaled saline (red) in patients at the age of 2 years: (C) without atopic eczema or allergic sensitisation (HR 1.38, 1.05-1.81; $p=0.02$ ); and (D) with either atopic eczema or allergic sensitisation ( $H R$ 0.77, $0.48-1.22 ; p=0.26$ ). $p$ values are from robust linear regression analyses. From The Lancet Respiratory Medicine, Skjerven HO, Rolfsjord LB, Berents TL, et al. Allergic diseases and the effect of inhaled epinephrine in children with acute bronchiolitis: follow-up from the randomized, controlled, double-blind, Bronchiolitis ALL trial 3 (9), 702-708. Copyright (C) (2015) Elsevier Limited. Reprinted with permission.

Atopic eczema or allergic sensitization did not significantly modify the response to the first inhalation of epinephrine measured by the change in clinical score $\left(p_{\text {interaction }}=0.37\right)$.

The presence of both atopic eczema and allergic sensitization $(n=11)$ at the age of two years did not significantly modify the effect of iRA on LOS $\left(p_{\text {interaction }}=0.24\right)$, with at difference in length of stay if receiving inhaled epinephrine versus saline of $+37.8 \mathrm{~h}(95 \% \mathrm{Cl}-24.8,100.2$; $p=0.21)$. In children without both of these features present $(n=283)$, the difference in length of stay was $-12.2 \mathrm{~h}(95 \% \mathrm{Cl}-24.8,0.4 ; \mathrm{p}=0.06)$.

There was no interaction between inhalant strategy (on-demand versus fixed schedule) and atopic eczema and allergic sensitization $\left(p_{\text {interaction }}=0.59\right)$ on the length of stay. Stratified analyses are presented in the appendix to paper\#3. 


\section{Discussion}

\subsection{The effect of racemic adrenaline versus saline on acute bronchiolitis}

In infants with acute bronchiolitis, treatment with inhaled racemic adrenaline was not associated with a shorter hospital stay than treatment with inhaled saline, nor with reduced use of ventilatory support, supplemental oxygen therapy, or nasogastric-tube feeding. There was an interaction between age and medication type; the youngest infants receiving inhaled racemic adrenaline tended to have a longer hospital stay.

The lack of effect of inhaled racemic adrenaline on length of hospital stay confirms similar findings in two previous studies on acute bronchiolitis; 1) A study by Patel et al, randomized 149 infants to receive racemic epinephrine, salbutamol or saline inhalations every 1 to 6 hours until discharge. ${ }^{50}$ 2) Wainwright et al randomized 194 infants to receive a total of three inhalations of either adrenaline or saline. ${ }^{49}$. Neither of these to studies independently nor a Cochrane meta-analysis ${ }^{40}$ of the 292 patients receiving adrenaline or saline, showed a significant effect on LOS.

The lack of significant improvement in clinical score in the present study was surprising in view of previous findings. A previous study in our research group demonstrated improved oxygenation and clinical signs 15-30 minutes after inhaled racemic adrenaline in hospitalized children aged less than 18 months with acute bronchiolitis ${ }^{44}$. Plint et al found improved clinical score (RDAI) during the first hour after inhalations with adrenaline in outpatient infants with acute bronchiolitis. ${ }^{109}$ However, a Cochrane review reported improved clinical score after adrenaline in outpatients, but not in inpatients with bronchiolitis. ${ }^{40}$ 
The significant interaction we noted between age and inhaled racemic adrenaline is of interest. To our knowledge, the influence of age on the response of inhaled bronchodilators in infants with bronchiolitis has not previously been reported. The tendency for the youngest infants receiving inhaled racemic adrenaline to have a longer hospital stay is in contrast to the reported effectiveness of inhaled racemic adrenaline for reducing vascular engorgement and edema. ${ }^{39}$ It may also be due to the finding that minimal handling (less inhalation treatments, see below) was beneficial, and possibly so in the youngest infants.

There are several reasons why inhalations with adrenaline might not be beneficial to all children. First, it is known that adrenaline may cause serious arrhythmia, and life threatening cardiac arrhythmia has been reported after a single dose in an infant with acute bronchiolitis ${ }^{110}$. Second, inhalations are commonly driven by $100 \%$ oxygen, which in itself may have a negative effect on the immature respiratory system on young infants ${ }^{111}$. Third, the combination of adrenaline, high concentration of oxygen and the inhalation procedure itself, including appliance of a tight mask, may cause a stress reaction in the child, with unknown pathophysiological and psychological impact. In addition, the administration of inhalations as standard treatment to all hospitalized children with acute bronchiolitis requires substantial nursing staff resources from already pressured paediatric wards during winter viral epidemics. Any measure in reducing non-efficacious inhalations given should therefore be sought. 


\subsection{On-demand versus fixed schedule administration}

In infants with acute bronchiolitis, administration of inhalations on demand was found to be superior to administration on a fixed schedule in reducing LOS, with the mean LOS 13.7 hours shorter for those receiving inhalations on demand, and in reducing the use of ventilatory support, supplemental oxygen therapy, and nasogastric-tube feeding. There was an interaction between age and inhalation strategy.

As acute bronchiolitis is the most common cause of admission to paediatric departments in the western world, we considered, in our prospective power analyses, a reduction in LOS of 5 hours to be clinically significant. Thus, a reduction of LOS of 14 hours in infants receiving inhalations on demand may have substantial clinical and financial implications.

Although not previously shown, the possibility that saline may have a bronchoconstrictive effect in the youngest infants (younger than 3 months of age) cannot be ruled out. Thus, the superiority of the on-demand schedule, in which fewer inhalations were administered, supports the goal of "minimal handling" (allowing infants to sleep, with minimal interruption) ${ }^{56}$ in acutely ill infants.

The physicians and nursing staffs were instructed to include their clinical judgment and were not provided with strict criteria for when to administer on-demand inhalations and criteria for discharge. Factors to consider included objective measures (e.g., oxygen saturation, respiratory rate, and clinical score) and subjective assessments (e.g., alertness and eating), as well as therapeutic response (with a better response leading to a higher priority of prescribing inhalation therapy) and timing (coordinating procedures that might cause stress in order to protect sleep and rest). 
However, possible varying practice among hospitals is unlikely to have influenced the main results, as we found no significant hospital-treatment interaction. 


\subsection{Virus detection and acute bronchiolitis}

In infants with acute bronchiolitis, we found no association between the presence of one or combinations of viruses (RSV and HRV, RSV only, no virus or $\geqslant 2$ viruses) and disease severity after adjustment for multiple testing. A high genomic viral load for RSV only, but not for any of the other viruses or combinations thereof was associated with increased LOS and more use of oxygen and ventilatory support. We found no associations between the presences of single or multiple airways viruses, including RSV and HRV and the treatment effect of inhaled racemic adrenaline versus saline inhalations.

The high rate (91\%) of virus detection, including RSV in $83 \%$ and co-infections in $61 \%$ is in line with a recent study from Finland ( $86 \%$ detection rate) of children with bronchiolitis, ${ }^{112}$ but is high compared to other studies ${ }^{75,83,92}$ (up to $41 \%$ co-infections). ${ }^{77,113}$ Interestingly, the Finnish study with a high identification rate of at least one virus reported only $15 \%$ of children with more than one virus, ${ }^{112}$ whereas in the same multicentre study including also 16 American study sites and of 2615 children $<2$ years of age with severe bronchiolitis, RSV was detected in $67 \%$, with additional viruses detected in $31 \% .{ }^{104}$ Further, approximately half of the prematurely born infants younger than 6 months of age in Brazil with lower respiratory tract infection and one identified virus had co-infection with at least one virus, most commonly RSV and HRV. ${ }^{114}$

Co-infections with up to seven viruses as well as $30 \%$ of children infected with three viruses or more have to our knowledge not previously been published. The differences in virus detection may be in part explained by modern and highly sensitive virus detection techniques, a relatively homogenous the study population of moderately to severely ill infants with a strict definition of acute bronchiolitis and the use of a structured 
nasopharyngeal aspirate procedure performed by trained and experienced personnel. Also, a large proportion ( $77 \%$ of one- to two-year olds, $96 \%$ of three- to five-year-olds) of young Norwegian children attend day-care centres ${ }^{115}$, which might increase the incidence and morbidity of respiratory virus infections ${ }^{116}$ that subsequently infect their infant siblings.

Although age adjusted analyses indicated a slightly longer LOS with coronavirus and shorter LOS with metapneumovirus in line with a previous report ${ }^{83}$, we found no significant association between type of virus other than RSV or co-infection (with two to seven viruses) and disease severity or LOS after adjusting for multiple testing in the present study. This is in contrast to previous reports of studies with fewer infants ( $n=180$ in each) ${ }^{92,117}$, as well as in the 61 premature infants with severe lower respiratory tract infections in Brazil, ${ }^{114}$ RSV combined with HRV was associated with increased LOS compared to RSV alone. Our findings are however, in line with the lack of association with disease severity and co-infections among the $31 \%$ of children less than two years of age with RSV and another virus in the largest virus study to date $(n=2615)$ in acute bronchiolitis. ${ }^{104}$ The clinical relevance of the presence of viruses known to be pathogenic, including influenza virus ${ }^{118}$, adenovirus ${ }^{119}$, bocavirus $^{120}$, coronavirus $^{121}$, parainfuenzavirus ${ }^{122}$ and metapneumovirus ${ }^{123}$, found in significant rates in our study population ( $n=37-56,10-15 \%)$ are not clear and could not be further elucidated due to lack of serial measurements in the absence of bronchiolitis.

Our novel approach with the use of cluster analyses to increase specificity showed that high genomic RSV load was associated with an increased severity of disease, in line with previous reports $^{75,88-91}$ and a recent report including more than 2000 children using a tertile approach to categorize genomic RSV load. ${ }^{104}$ Cluster analyse has the advantage that it can take into account the pattern of genomic load individually for each virus. The presence of high 
genomic load of RSV and HRV in combination was also associated with significantly increased LOS, in line with the findings in premature infants in Brazil. However, we were not able to investigate if this was due to co-infection or mainly related to the high genomic load.

In the present study, the percentage of children with more than one virus (coinfection) decreased from $61 \%$ to $18 \%$ by considering high genomic load only. Identification of viruses does not necessarily infer causal associations with bronchiolitis, as suggested by the present study. However, the very high rate of RSV, very low rates of mono-infections with viruses other than RSV and lack of association between HRV (A/B or C) or multiple viruses detected with disease severity, support the dominating role of RSV in acute bronchiolitis. The association between high genomic load of RSV and disease severity further supports the importance of RSV.

The detection rates of HRV in young children have previously been found to be similar regardless of the presence of a symptomatic airway infection, as recently Yoshida et al showed, comparing hospitalized patients (mean age 1,5 years), finding HRV in $35 \%$ of controls versus in $29 \%$ of patients (RSV was detected in $3 \%$ of controls versus $39 \%$ of patients) ${ }^{124}$. However, the role of HRV C in initiating, triggering or perpetuating early obstructive airways disease has been unclear. Bizzintino et al found an association between HRV C and severity of acute asthma ${ }^{87}$ in children more than two years of age, while Cox et al $^{125}$ found increased hospital admissions in 197 children less than five (mean age 31.0 months) years of age. It remains to be shown to what extent detection of HRV C in infants with bronchiolitis may relate to future asthma.

The present study found no evidence for effect modification of inhaled racemic adrenaline by RSV, HRV or multiple viruses detected, neither in regular or high specificity analyses. 
Mansbach et $\mathrm{al}^{76}$ suggested in 2010 that future clinical trials should categorize results by infectious pathogen, including HRV, as such information was lacking. Our negative result does not support the use of bronchodilators to be guided by viral aetiology. 


\subsection{The influence of allergic disease on the effect of treatment of acute}

bronchiolitis

The present study tested the hypothesis that the subgroup of children with a disposition for, or would develop allergic disease may have beneficial effect of racemic adrenaline inhalations during hospital admission with moderate-to-severe acute bronchiolitis in infancy. Contrary to our hypothesis, children with recurrent bronchial obstruction, atopic eczema, or allergic sensitization, by the age of two years had no significant effect of the treatment, whereas patients without atopic eczema or allergic sensitization by the age of two years had a significantly shorter length of stay if treated with inhaled epinephrine versus saline.

The effect of bronchodilators in acute bronchiolitis has been the subject of debate. Major guidelines recommend a restrictive approach, ${ }^{2,453}$ based on evidence showing no effect of any bronchodilator on the most clinically relevant parameters such as length of stay and the use of supportive care. ${ }^{40,73,126,127}$ Despite this, inhaled bronchodilators (including epinephrine) are still used in most patients in several countries, including the USA, Sweden, and Finland. ${ }^{31,42}$ Sustained frequent use of inhaled bronchodilators is presumably due to a belief in the existence of one or more subgroup(s) of patients that benefit from such treatment.

The present study is to our knowledge the first to report a potential treatment effect in subgroups of patients with recurrent bronchial obstruction, allergic sensitization, or atopic eczema up to the age of two years. Our findings show that not only was there a lack of effect of inhaled epinephrine in children who went on to have recurrent bronchial obstruction episodes, atopic eczema, or allergic sensitization, but rather that children without these diseases appeared to benefit from inhaled racemic epinephrine. The findings in our study contrast with the hypothesis that inhaled epinephrine might be beneficial in children 
developing asthma, atopic disease, or allergy, ${ }^{101}$ which has wide support among clinicians. It is not clear why children without atopic eczema or allergic sensitization responded to inhaled epinephrine, whereas those with one or both of these conditions did not. The rationale for the use of the non-selective adrenergic agonist epinephrine has been the potential effect on vascular engorgement and mucosal swelling that adds to the dilating effect of $\beta$-2-adrenergic selective agonists on bronchial smooth muscle. However, it is not clear when chronic inflammation starts in the airways of children with asthma, although it has been suggested that some children with pre-school wheezing develop airway remodelling at a very early stage. ${ }^{26,128,129}$ Airway obstruction in acute bronchiolitis usually occurs in the bronchioles involving exaggerated cytopathology with neutrophil-dominated inflammatory changes with subsequent shedding of infected epithelium and sub-mucosal oedema. ${ }^{130}$ However, we speculate that children who develop atopic disease might already have an altered airway response to the viral infection, ${ }^{26}$ with chronic inflammatory changes possibly adding to the reduced airway calibre in response to the viral infection. A possible reduction in airway oedema by racemic epinephrine might attenuate airway obstruction and improve recovery in children without chronic inflammatory responses associated with allergic sensitization or atopic eczema. However, findings from a randomized controlled trial have shown that palivizumab, a monoclonal antibody against respiratory syncytial virus, reduced subsequent episodes of wheeze, and the authors suggested that a RSV infection in infancy may cause epithelial damage and itself contribute to the pathogenesis of recurrent wheeze. $^{23}$

Our results suggest that the differential response to epinephrine might reflect variations in underlying pathophysiological mechanisms in children with and without allergic disease developing by 2 years of age. High genomic load of respiratory syncytial virus has been 
associated with severity in clinical studies, including a large multicentre study ${ }^{104}$ that corroborated the involvement of Th-2 (IL-4 and IL-6) cytokines ${ }^{131}$ and interferon ${ }^{91}$ in severe acute bronchiolitis. However, we can only speculate that the shorter length of stay in children without atopic disease who received inhaled epinephrine could be associated with a less pronounced Th-2 type inflammatory response to the virus, but we do not have any evidence to support this hypothesis.

The diagnosis and definitions of asthma in infants and pre-school children is highly variable. We therefore chose to report recurrent bronchial obstruction, often referred to as recurrent wheeze. ${ }^{132}$ In line with other studies as well as the definition of asthma described in the Nordic consensus report on asthma management, ${ }^{133}$ our definition of recurrent bronchial obstruction was set to at least three episodes. We therefore did not make any decision as to whether or not the children by two years had asthma. Our clinical responder analyses $(64 \%$ in each group, letter to the editor, amendment to paper \#1) does not support that subgroups of patients have transient response to epinephrine.

Racemic epinephrine did not show benefit in children with increased risk of asthma. In the present study we were not able to identify relevant subgroups at the time of acute bronchiolitis thus restricting the clinical applicability of choosing individuals who would potentially benefit from inhaled racemic epinephrine. We found no significant treatment differences based on allergic disease risk at the time of hospital admission, possibly because atopic eczema had not yet developed for most infants. However, as the study population in the present study is similar to those described from other parts of the world, our results are likely to be generalizable to patients hospitalised with acute bronchiolitis during infancy. 
Our study does not support a trial of inhaled epinephrine in children with increased risk of allergic diseases. 


\subsection{Strength and limitations}

Our study of two inhalation solutions was sufficiently powered to allow detection of a 5-hour difference in length of stay and to perform subgroup analyses for the major outcomes. The study included a nationally representative patient cohort with the expected patterns of viral infection. In addition, the study was managed in accordance with local and national guidelines. Despite the limited power of the study to detect an interaction between the interventions, the observed interaction was approximately one third of the 5-hour length of stay selected a priori as a clinically relevant difference. ${ }^{106}$

Finding an infant ready for discharge from the hospital depended on objective measures of disease severity and the use of supportive care, social factors (parental skills and resources), geography (distance from home to hospital), and even hospital administrative factors (prioritization of patients in a crowded ward). We believe that the pragmatic approach increases generalizability of this study and is rather a strength than a limitation.

The initially planned end point for LOS, which was the time at which the child was deemed ready for discharge, was not recorded for 83 children (Figure 1). We therefore used the actual time of discharge for all children. The results were similar with the use of these two end points (Table S5 in the Supplementary Appendix of Paper \#1).

The clinical scoring (Table 1) used in the present study had previously been used in a Scandinavian study, ${ }^{44}$ but was, in line with other scoring systems of acute bronchiolitis, not validated. ${ }^{134}$ The commonly used Respiratory Distress Assessment Instrument ${ }^{135}$ was considered to be too specific and therefore not chosen for the study. 
In contrast to most other studies, this study allowed inclusion of patients with one previous episode of wheeze. Subgroup analyses of patients with no previous wheeze $(n=264)$ showed similar results of the main outcome (LOS) as the total population (Table 9).

The present study population was insufficient for robust subgroup analyses for all types of viruses. However, it is likely that analyses of the major viruses, RSV and HRV are sufficiently large to indicate the lack of clinically relevant associations.

Although interaction tests are considered appropriate for detecting effect modification, these analyses generally requires four times the population size to detect significant differences of similar magnitude. ${ }^{136}$ However, the study population in the present study is large, and we have a high detection rate of the major viruses. Nevertheless the lack of significant interaction must be interpreted with caution.

We believe the follow-up rate of $73 \%$ (294/404) of children was acceptable due to the nature of the study, including moderately to severely ill infants during acute illness. The study population is reasonably sized for subgroup analyses in terms of major outcomes. Loss to follow-up is unlikely to bias the results because the parents were masked for treatment allocation, and the characteristics of the randomization groups were similar. 


\section{Implications of the study}

The documentation of the lack of effect of inhaled adrenaline compared to saline in children hospitalized with acute bronchiolitis had immediate impact on national clinical guidelines in Norway. Adrenaline inhalations are, from 2013, no longer advised as standard therapy to infants with acute bronchiolitis, although it is kept as an optional treatment to infants more than three months of age. The American Academy of Pediatrics' revision of guidelines in October $2014,{ }^{4}$ that now recommend against any use of inhaled bronchodilators in children with acute bronchiolitis, is partly based on the results reported from our study. ${ }^{73,137}$

UptoDate (www.uptodate.com), a leading globally treatment guideline, amended a recommendation of treatment on demand rather than on a fixed schedule, shortly after the publication of our study in 2013. Furthermore, treatment on demand was, shortly after publication, included in Norwegian guidelines.

The lack of association between virus coinfection and severity of disease may contribute to the current debate on whether or not hospitalized infants with acute bronchiolitis should be isolated. Isolation regimes are resource demanding, both on space and personnel. ${ }^{53}$ However, specifically designed intervention studies are needed to answer this question.

Accompanying our report in the Lancet Respiratory Medicine ${ }^{138}$, an editorial comment discussed the lack of effect of inhaled adrenaline on hospital stay in children that later develop recurrent bronchial obstruction, atopic eczema or allergic sensitization, ${ }^{137}$ In line with our conclusions, it was pointed out that the study provided further evidence to support a restrictive use of bronchodilators in children acute bronchiolitis. 
Bronchodilators are still being used in most hospitalized infants in several countries, including USA, Sweden and Finland. Full implementation of stricter guidelines on inhalation treatment in children with acute bronchiolitis will reduce the use of resources on administration of medication in this large patient group, sparing the vulnerable infant patients from a potentially stressful treatment with adrenaline and concentrate the focus of management to optimizing the use of supportive care. 


\section{Main conclusions}

\subsection{Is inhaled racemic adrenaline effective in acute bronchiolitis in}

hospitalized infants? (paper \#1)

In hospitalized children with acute bronchiolitis, inhaled racemic adrenaline was not superior to inhaled saline with regard to the length of hospital stay, the use of supportive treatment or clinical score.

\subsection{Is inhalation treatment "on demand" superior to "fixed schedule" in acute bronchiolitis in hospitalized infants? (paper \#1)}

Treatment with inhalations of racemic adrenaline or saline "on demand" was superior to treatment on a fixed schedule in children hospitalized with bronchiolitis, in terms of a shorter length of hospital stay, less use of oxygen support and less use of ventilatory support. Subgroup analyses showed that the benefit was mainly found in infants less than three months of age.

\subsection{What is the role of airway viruses in acute bronchiolitis with respect to severity of disease and treatment response of inhaled adrenaline?}

\section{(paper \#2)}

In acute bronchiolitis in infants, coinfection of respiratory viruses was found in $61 \%$ of the patients, with up to seven viruses simultaneously detected. Disease severity was not associated with virus type or coinfection, but a high genomic load of RSV was associated with a longer length of hospital stay and more use of oxygen and ventilatory support. Neither the presence of viruses, nor the viral genomic load modified the treatment response to inhaled adrenaline. 


\subsection{What is the role of allergic disease, present at the time of the acute}

bronchiolitis or later, with respect to treatment response? (paper \#1,3)

We found no evidence to support a beneficial effect of inhaled racemic adrenalin in infants who subsequently developed recurrent bronchial obstruction, atopic eczema or allergic sensitization in terms of hospital length of stay for bronchiolitis. The present study does not support an individual trial of inhaled adrenaline in acute bronchiolitis in children with increased risk of allergic diseases. 


\section{Future perspectives}

We believe the guideline changes in the United States (2014) and Norway (2013) were important steps in order to adjust the focus in the treatment of acute bronchiolitis towards a minimal handling approach, in line with current evidence from other's and ours studies. The guidelines might be further revised in Norway, based on our latest results, but the major advantages may now be achieved in enforcing implementation of these guidelines in daily clinical practice in paediatric clinics nation- and worldwide.

Further trials on inhaled the commonly used bronchodilators in children with acute bronchiolitis are not likely to be helpful. However, the effects whether positive or negative of the of inhaled saline in many hospitals has not been evaluated. Our study results showing that fewer inhalations were associated with reduced LOS indicate that the use of inhaled solutions should be tested for efficacy before extensive use.

Trials on the use of supportive care in this patient group are needed. There is little consensus on the limits (target for saturation of peripheral blood) for and type of administration of oxygen (flow rate, humidification). The use of ventilatory support is also debated, particularly in regards to non-invasive support (HFNC (high flow nasal cannula) and CPAP (continuous positive airway pressure)). Although considered crucial in the management of infants with severe acute bronchiolitis, few studies have systematically evaluated the use of CPAP, and no randomized trials on the use of HFNC have yet been published.

We suggest that clinical trials on infants with acute bronchiolitis, particularly on inhalation therapy, should include an option of no treatment, in line with the minimal handling approach. 


\section{References}

1. Court SD. The definition of acute respiratory illnesses in children.

PostgradMedJ 1973; 49(577): 771-6.

2. Zorc JJ, Hall CB. Bronchiolitis: recent evidence on diagnosis and management. Pediatrics 2010; 125(2): 342-9.

3. Nagakumar P, Doull I. Current therapy for bronchiolitis. Archives of disease in childhood 2012; 97: 827-30.

4. Ralston SL, Lieberthal AS, Meissner HC, et al. Clinical practice guideline: the diagnosis, management, and prevention of bronchiolitis. Pediatrics 2014; 134(5): e1474-502.

5. Wainwright C. Acute viral bronchiolitis in children- a very common condition with few therapeutic options. Paediatric respiratory reviews 2010; 11(1): 39-45; quiz

6. Carroll KN, Gebretsadik T, Griffin MR, et al. Increasing burden and risk factors for bronchiolitis-related medical visits in infants enrolled in a state health care insurance plan. Pediatrics 2008; 122(1): 58-64.

7. Carlsen KH, Orstavik I, Halvorsen K. Viral infections of the respiratory tract in hospitalized children. A study from Oslo during a 90 months' period. Acta Paediatr Scand 1983; 72(1): 53-8.

8. Orstavik I, Carlsen KH, Halvorsen K. Respiratory syncytial virus infections in Oslo 1972--1978. I. Virological and epidemiological studies. Acta Paediatr Scand 1980; 69(6): 717-22.

9. Fjaerli HO, Farstad T, Bratlid D. Hospitalisations for respiratory syncytial virus bronchiolitis in Akershus, Norway, 1993-2000: a population-based retrospective study. BMC Pediatr 2004; 4(1): 25.

10. Murray J, Bottle A, Sharland M, et al. Risk Factors for Hospital Admission with RSV Bronchiolitis in England: A Population-Based Birth Cohort Study. PLoS One 2014; 9(2): e89186.

11. American Academy of Pediatrics Subcommittee on D, Management of B. Diagnosis and management of bronchiolitis. Pediatrics 2006; 118(4): 1774-93.

12. Stockman LJ, Curns AT, Anderson LJ, Fischer-Langley G. Respiratory syncytial virus-associated hospitalizations among infants and young children in the United States, 1997-2006. The Pediatric infectious disease journal 2012; 31(1): 5-9. 
13. Thorburn K. Pre-existing disease is associated with a significantly higher risk of death in severe respiratory syncytial virus infection. Arch Dis Child 2009; 94(2): 99-103.

14. Choi J, Lee GL. Common pediatric respiratory emergencies. Emerg Med Clin North Am 2012; 30(2): 529-63, x.

15. Sigurs N. Respiratory syncytial virus lower respiratory tract illness in infancy and subsequent morbidity. Acta Paediatr 2007; 96(2): 156-7.

16. Piippo-Savolainen E, Korppi M. Wheezy babies--wheezy adults? Review on long-term outcome until adulthood after early childhood wheezing. Acta Paediatr 2008; 97(1): 5-11.

17. Sigurs N, Aljassim F, Kjellman B, et al. Asthma and allergy patterns over 18 years after severe RSV bronchiolitis in the first year of life. Thorax 2010; 65(12): 1045-52.

18. Mikalsen IB, Halvorsen T, Eide GE, Oymar K. Severe bronchiolitis in infancy: can asthma in adolescence be predicted? Pediatr Pulmonol 2013; 48(6): 538-44.

19. Turunen R, Koistinen A, Vuorinen T, et al. The first wheezing episode: respiratory virus etiology, atopic characteristics, and illness severity. Pediatr Allergy Immunol 2014; 25(8): 796-803.

20. Backman K, Piippo-Savolainen E, Ollikainen H, Koskela H, Korppi M. Irreversible airway obstruction in adulthood after bronchiolitis in infancy: evidence from a 30-year follow-up study. Respir Med 2014; 108(1): 218-23.

21. Carlsen KH, Larsen S, Orstavik I. Acute bronchiolitis in infancy. The relationship to later recurrent obstructive airways disease. Eur J Respir Dis 1987; 70(2): 86-92.

22. Kristjansson S, Wennergren D, Eriksson B, Thorarinsdottir H, Wennergren G. U-EPX levels and wheezing in infants and young children with and without RSV bronchiolitis. Respir Med 2006; 100(5): 878-83.

23. Blanken MO, Rovers MM, Molenaar JM, et al. Respiratory syncytial virus and recurrent wheeze in healthy preterm infants. $N$ Engl J Med 2013; 368(19): 1791-9.

24. Wu P, Dupont WD, Griffin MR, et al. Evidence of a causal role of winter virus infection during infancy in early childhood asthma. Am J Respir Crit Care Med 2008; 178(11): 1123-9.

25. Chanock R, Finberg L. Recovery from infants with respiratory illness of a virus related to chimpanzee coryza agent (CCA). II. Epidemiologic aspects of infection in infants and young children. Am J Hyg 1957; 66(3): 291-300. 
26. Holt PG, Sly PD. Viral infections and atopy in asthma pathogenesis: new rationales for asthma prevention and treatment. Nat Med 2012; 18(5): 726-35.

27. Thomas AO, Lemanske RF, Jr., Jackson DJ. Infections and their role in childhood asthma inception. Pediatr Allergy Immunol 2014; 25(2): 122-8.

28. Mansbach JM, Piedra PA, Stevenson MD, et al. Prospective multicenter study of children with bronchiolitis requiring mechanical ventilation. Pediatrics 2012; 130(3): e492-500.

29. Wang EE, Law BJ, Stephens D. Pediatric Investigators Collaborative Network on Infections in Canada (PICNIC) prospective study of risk factors and outcomes in patients hospitalized with respiratory syncytial viral lower respiratory tract infection. J Pediatr 1995; 126(2): 212-9.

30. Ricci V, Delgado Nunes V, Murphy MS, Cunningham S, Guideline Development G, Technical T. Bronchiolitis in children: summary of NICE guidance. BMJ 2015; 350: h2305.

31. Parikh K, Hall M, Teach SJ. Bronchiolitis management before and after the AAP guidelines. Pediatrics 2014; 133(1): e1-7.

32. Vogel AM, Lennon DR, Harding JE, et al. Variations in bronchiolitis management between five New Zealand hospitals: can we do better? J Paediatr Child Health 2003; 39(1): 40-5.

33. Biezen R, Pollack AJ, Harrison C, et al. Respiratory tract infections among children younger than 5 years: current management in Australian general practice. Med J Aust 2015; 202(5): 262-5.

34. Ho SW, Huang KY, Teng YH, Ku MS, Chiou JY. Practice Variations between Emergency Physicians and Pediatricians in Treating Acute Bronchiolitis in the Emergency Department: A Nationwide Study. J Emerg Med 2015.

35. Plint AC, Grenon R, Klassen TP, Johnson DW. Bronchodilator and steroid use for the management of bronchiolitis in Canadian pediatric emergency departments. CJEM 2015; 17(1): 46-53.

36. Law BJ, De Carvalho V. Respiratory syncytial virus infections in hospitalized Canadian children: regional differences in patient populations and management practices. The Pediatric Investigators Collaborative Network on Infections in Canada. Pediatr Infect Dis J 1993; 12(8): 659-63.

37. Newcomb RW. Use of adrenergic bronchodilators by pediatric allergists and pulmonologists. Am J Dis Child 1989; 143(4): 481-5. 
38. Kimpen JL, Schaad UB. Treatment of respiratory syncytial virus bronchiolitis: 1995 poll of members of the European Society for Paediatric Infectious Diseases. Pediatr Infect Dis J 1997; 16(5): 479-81.

39. Wohl ME, Chernick V. State of the art: bronchiolitis. Am Rev Respir Dis 1978; 118(4): 759-81.

40. Hartling L, Bialy LM, Vandermeer B, et al. Epinephrine for bronchiolitis. CochraneDatabaseSystRev 2011; (6): CD003123.

41. Pettersen MH, T; Carlsen KH. Akutt Bronkiolitt. Veileder i akutt pediatri 2006.

42. Mecklin M, Hesselmar B, Qvist E, Wennergren G, Korppi M. Diagnosis and treatment of bronchiolitis in Finnish and Swedish children's hospitals. Acta Paediatr 2014.

43. Hariprakash S, Alexander J, Carroll W, et al. Randomized controlled trial of nebulized adrenaline in acute bronchiolitis. PediatrAllergy Immunol 2003; 14(2): 134-9.

44. Kristjansson S, Lodrup Carlsen KC, Wennergren G, Strannegard IL, Carlsen $\mathrm{KH}$. Nebulised racemic adrenaline in the treatment of acute bronchiolitis in infants and toddlers. ArchDisChild 1993; 69(6): 650-4.

45. Lodrup Carlsen KC, Carlsen KH. Inhaled nebulized adrenaline improves lung function in infants with acute bronchiolitis. RespirMed 2000; 94(7): 709-14.

46. Menon K, Sutcliffe T, Klassen TP. A randomized trial comparing the efficacy of epinephrine with salbutamol in the treatment of acute bronchiolitis. JPediatr 1995; 126(6): 1004-7.

47. Reijonen T, Korppi M, Pitkakangas S, Tenhola S, Remes K. The clinical efficacy of nebulized racemic epinephrine and albuterol in acute bronchiolitis. ArchPediatrAdolescMed 1995; 149(6): 686-92.

48. Sanchez I, De KJ, Powell RE, Wolstein R, Chernick V. Effect of racemic epinephrine and salbutamol on clinical score and pulmonary mechanics in infants with bronchiolitis. JPediatr 1993; 122(1): 145-51.

49. Wainwright $\mathrm{C}$, Altamirano L, Cheney M, et al. A multicenter, randomized, double-blind, controlled trial of nebulized epinephrine in infants with acute bronchiolitis. N Engl J Med 2003; 349(1): 27-35.

50. Patel H, Platt RW, Pekeles GS, Ducharme FM. A randomized, controlled trial of the effectiveness of nebulized therapy with epinephrine compared with albuterol and saline in infants hospitalized for acute viral bronchiolitis. JPediatr 2002; 141(6): 818-24. 
51. Langley JM, Smith MB, LeBlanc JC, Joudrey H, Ojah CR, Pianosi P. Racemic epinephrine compared to salbutamol in hospitalized young children with bronchiolitis; a randomized controlled clinical trial [ISRCTN46561076]. BMCPediatr 2005; 5(1): 7.

52. Diagnosis and management of bronchiolitis. Pediatrics 2006; 118(4): 177493.

53. Baumer JH. SIGN guideline on bronchiolitis in infants. ArchDisChild EducPractEd 2007; 92(5): ep149-ep51.

54. Pettersen MH, T; Carlsen KH. Akutt bronkiolitt. Veileder i akutt pediatri. Oslo, Norway: Den norske lægeforening; 2007: 198-201.

55. Zhang L, Sanguebsche LS. [The safety of nebulization with 3 to $5 \mathrm{ml}$ of adrenaline (1:1000) in children: an evidence based review]. J Pediatr (Rio J) 2005; 81(3): 193-7.

56. Murdoch DR, Darlow BA. Handling during neonatal intensive care. Arch Dis Child 1984; 59(10): 957-61.

57. Smyth RL, Openshaw PJ. Bronchiolitis. Lancet 2006; 368(9532): 312-22.

58. Beem M, Wright FH, Hamre D, Egerer R, Oehme M. Association of the chimpanzee coryza agent with acute respiratory disease in children. $N$ Engl J Med 1960; 263: 523-30.

59. Chanock RM, Kim HW, Vargosko AJ, et al. Respiratory syncytial virus. I. Virus recovery and other observations during 1960 outbreak of bronchiolitis, pneumonia, and minor respiratory diseases in children. JAMA 1961; 176: 647-53.

60. Johnson KM, Chanock RM, Rifkind D, Kravetz HM, Knight V. Respiratory syncytial virus. IV. Correlation of virus shedding, serologic response, and illness in adult volunteers. JAMA 1961; 176: 663-7.

61. Kravetz HM, Knight V, Chanock RM, et al. Respiratory syncytial virus. III. Production of illness and clinical observations in adult volunteers. JAMA 1961; 176: 657-63.

62. Parrott RH, Vargosko AJ, Kim HW, et al. Respiratory syncytial virus. II. Serologic studies over a 34-month period of children with bronchiolitis, pneumonia, and minor respiratory diseases. JAMA 1961; 176: 653-7.

63. Jartti T, Lehtinen P, Vuorinen T, Ruuskanen O. Bronchiolitis: age and previous wheezing episodes are linked to viral etiology and atopic characteristics. Pediatr Infect Dis J 2009; 28(4): 311-7. 
64. Midulla F, Pierangeli A, Cangiano G, et al. Rhinovirus bronchiolitis and recurrent wheezing: 1-year follow-up. Eur Respir J 2012; 39(2): 396-402.

65. Mikalsen IB, Halvorsen T, Oymar K. The outcome after severe bronchiolitis is related to gender and virus. Pediatr Allergy Immunol 2012; 23(4): 391-8.

66. Skjerven HO, Megremis S, Papadopoulos NG, Mowinckel P, Carlsen KH, Lodrup Carlsen KC. Virus type and genomic load in acute bronchiolitis: severity and treatment response with inhaled adrenaline. J Infect Dis 2015.

67. Hall CB, Weinberg GA, Iwane MK, et al. The burden of respiratory syncytial virus infection in young children. $N$ Engl J Med 2009; 360(6): 588-98.

68. Spence L, Barratt N. Respiratory syncytial virus associated with acute respiratory infections in Trinidadian patients. Am J Epidemiol 1968; 88(2): 25766.

69. Sung RY, Murray HG, Chan RC, Davies DP, French GL. Seasonal patterns of respiratory syncytial virus infection in Hong Kong: a preliminary report. J Infect Dis 1987; 156(3): 527-8.

70. McQuillin J, Gardner PS. Rapid diagnosis of respiratory syncytial virus infection by immunofluorescent antibody techniques. $\mathrm{Br}$ Med J 1968; 1(5592): 602-5.

71. Leinikki PO, Passila S. Quantitative, semiautomated, enzyme-linked immunosorbent assay for viral antibodies. J Infect Dis 1977; 136 Suppl: S294-9.

72. Paton AW, Paton JC, Lawrence AJ, Goldwater PN, Harris RJ. Rapid detection of respiratory syncytial virus in nasopharyngeal aspirates by reverse transcription and polymerase chain reaction amplification. J Clin Microbiol 1992; 30(4): 901-4.

73. Skjerven HO, Hunderi JO, Brugmann-Pieper SK, et al. Racemic adrenaline and inhalation strategies in acute bronchiolitis. $N$ Engl J Med 2013; 368(24): 2286-93.

74. Dollner H, Risnes K, Radtke A, Nordbo SA. Outbreak of human metapneumovirus infection in norwegian children. Pediatr Infect Dis J 2004; 23(5): 436-40.

75. Brand HK, de Groot R, Galama JM, et al. Infection with multiple viruses is not associated with increased disease severity in children with bronchiolitis. Pediatr Pulmonol 2012; 47(4): 393-400.

76. Mansbach JM, Piedra PA, Teach SJ, et al. Prospective Multicenter Study of Viral Etiology and Hospital Length of Stay in Children With Severe Bronchiolitis. Arch Pediatr Adolesc Med 2012; 166: 700-6. 
77. Bamberger E, Srugo I, Abu Raya B, et al. What is the clinical relevance of respiratory syncytial virus bronchiolitis?: findings from a multi-center, prospective study. Eur J Clin Microbiol Infect Dis 2012; 31(12): 3323-30.

78. Hervas D, Reina J, Yanez A, del Valle JM, Figuerola J, Hervas JA. Epidemiology of hospitalization for acute bronchiolitis in children: differences between RSV and non-RSV bronchiolitis. Eur J Clin Microbiol Infect Dis 2012; 31(8): 1975-81.

79. Papadopoulos NG, Moustaki M, Tsolia M, et al. Association of rhinovirus infection with increased disease severity in acute bronchiolitis. Am J Respir Crit Care Med 2002; 165(9): 1285-9.

80. Calvo C, Pozo F, Garcia-Garcia ML, et al. Detection of new respiratory viruses in hospitalized infants with bronchiolitis: a three-year prospective study. Acta paediatrica 2010; 99(6): 883-7.

81. Jartti T, Jartti L, Peltola V, Waris M, Ruuskanen O. Identification of respiratory viruses in asymptomatic subjects: asymptomatic respiratory viral infections. Pediatr Infect Dis J 2008; 27(12): 1103-7.

82. Miller EK, Williams JV, Gebretsadik T, et al. Host and viral factors associated with severity of human rhinovirus-associated infant respiratory tract illness. J Allergy Clin Immunol 2011; 127(4): 883-91.

83. Marguet $\mathrm{C}$, Lubrano M, Gueudin M, et al. In very young infants severity of acute bronchiolitis depends on carried viruses. PLoS One 2009; 4(2): e4596.

84. Amat F, Henquell C, Verdan M, Roszyk L, Mulliez A, Labbe A. Predicting the severity of acute bronchiolitis in infants: Should we use a clinical score or a biomarker? J Med Virol 2013.

85. Lee WM, Kiesner C, Pappas T, et al. A diverse group of previously unrecognized human rhinoviruses are common causes of respiratory illnesses in infants. PLoS One 2007; 2(10): e966.

86. Miller EK, Khuri-Bulos N, Williams JV, et al. Human rhinovirus C associated with wheezing in hospitalised children in the Middle East. J Clin Virol 2009; 46(1): 85-9.

87. Bizzintino J, Lee WM, Laing IA, et al. Association between human rhinovirus $\mathrm{C}$ and severity of acute asthma in children. Eur Respir J 2011; 37(5): 1037-42.

88. DeVincenzo JP, El Saleeby CM, Bush AJ. Respiratory syncytial virus load predicts disease severity in previously healthy infants. J Infect Dis 2005; 191(11): 1861-8. 
89. El Saleeby CM, Bush AJ, Harrison LM, Aitken JA, Devincenzo JP. Respiratory syncytial virus load, viral dynamics, and disease severity in previously healthy naturally infected children. J Infect Dis 2011; 204(7): 996-1002.

90. Fodha I, Vabret A, Ghedira L, et al. Respiratory syncytial virus infections in hospitalized infants: association between viral load, virus subgroup, and disease severity. J Med Virol 2007; 79(12): 1951-8.

91. Scagnolari C, Midulla F, Selvaggi C, et al. Evaluation of viral load in infants hospitalized with bronchiolitis caused by respiratory syncytial virus. Med Microbiol Immunol 2012; 201(3): 311-7.

92. Richard N, Komurian-Pradel F, Javouhey E, et al. The impact of dual viral infection in infants admitted to a pediatric intensive care unit associated with severe bronchiolitis. Pediatr Infect Dis J 2008; 27(3): 213-7.

93. Wahn U. What drives the allergic march? Allergy 2000; 55(7): 591-9.

94. Lodrup Carlsen KC, Mowinckel P, Hovland V, Haland G, Riiser A, Carlsen KH. Lung function trajectories from birth through puberty reflect asthma phenotypes with allergic comorbidity. J Allergy Clin Immunol 2014; 134(4): 917-23 e7.

95. Pinart M, Benet M, Annesi-Maesano I, et al. Comorbidity of eczema, rhinitis, and asthma in IgE-sensitised and non-IgE-sensitised children in MeDALL: a population-based cohort study. Lancet Respir Med 2014; 2(2): 131-40.

96. Sigurs N, Gustafsson PM, Bjarnason R, et al. Severe respiratory syncytial virus bronchiolitis in infancy and asthma and allergy at age 13. AmJRespirCrit Care Med 2005; 171(2): 137-41.

97. Teo SM, Mok D, Pham K, et al. The infant nasopharyngeal microbiome impacts severity of lower respiratory infection and risk of asthma development. Cell Host Microbe 2015; 17(5): 704-15.

98. Bousquet J, Yssel H, Vignola AM. Is allergic asthma associated with delayed fetal maturation or the persistence of conserved fetal genes? Allergy 2000; 55(12): 1194-7.

99. Holt PG, Macaubas C, Stumbles PA, Sly PD. The role of allergy in the development of asthma. Nature 1999; 402(6760 Suppl): B12-7.

100. Bousquet J, Anto JM, Wickman M, et al. Are allergic multimorbidities and IgE polysensitization associated with the persistence or re-occurrence of foetal type 2 signalling? The MeDALL hypothesis. Allergy 2015; 70(9): 1062-78.

101. Mittal V, Darnell C, Walsh B, et al. Inpatient bronchiolitis guideline implementation and resource utilization. Pediatrics 2014; 133(3): e730-7. 
102. Chun JY, Kim KJ, Hwang IT, et al. Dual priming oligonucleotide system for the multiplex detection of respiratory viruses and SNP genotyping of CYP2C19 gene. Nucleic Acids Res 2007; 35(6): e40.

103. Wisdom A, Leitch EC, Gaunt E, Harvala H, Simmonds P. Screening respiratory samples for detection of human rhinoviruses (HRVs) and enteroviruses: comprehensive VP4-VP2 typing reveals high incidence and genetic diversity of HRV species C. J Clin Microbiol 2009; 47(12): 3958-67.

104. Hasegawa K, Jartti T, Mansbach JM, et al. Respiratory syncytial virus genomic load and disease severity among children hospitalized with bronchiolitis: multicenter cohort studies in the United States and Finland. J Infect Dis 2015; 211(10): 1550-9.

105. Hanifin JM. Diagnostic features of atopic dermatitis. Acta Derm Venereol 1980; 92(suppl): 44-7.

106. Panickar J, Lakhanpaul M, Lambert PC, et al. Oral prednisolone for preschool children with acute virus-induced wheezing. $N$ Engl J Med 2009; 360(4): 329-38.

107. Wang R, Lagakos SW, Ware JH, Hunter DJ, Drazen JM. Statistics in medicine-reporting of subgroup analyses in clinical trials. N Engl J Med 2007; 357(21): 2189-94.

108. Sormani MP, Bruzzi P. Reporting of subgroup analyses from clinical trials. Lancet Neurol 2012; 11(9): 747; author reply -8.

109. Plint AC, Johnson DW, Patel H, et al. Epinephrine and dexamethasone in children with bronchiolitis. N Engl J Med 2009; 360(20): 2079-89.

110. Toaimah FH, Al-Ansari K. Life-threatening cardiac arrhythmia after a single dose of nebulized epinephrine in pediatric emergency department. J Trop Pediatr 2011; 57(6): 497-9.

111. Saugstad OD, Ramji S, Soll RF, Vento M. Resuscitation of newborn infants with $21 \%$ or $100 \%$ oxygen: an updated systematic review and meta-analysis. Neonatology 2008; 94(3): 176-82.

112. Jartti T, Aakula M, Mansbach JM, et al. Hospital length-of-stay is associated with rhinovirus etiology of bronchiolitis. Pediatr Infect Dis J 2014; 33(8): 829-34.

113. Miron D, Srugo I, Kra-Oz Z, et al. Sole pathogen in acute bronchiolitis: is there a role for other organisms apart from respiratory syncytial virus? Pediatr Infect Dis J 2010; 29(1): e7-e10.

114. Arruda E, Jones MH, Escremim de Paula F, et al. The burden of single virus and viral coinfections on severe lower respiratory tract infections among preterm 
infants: a prospective birth cohort study in Brazil. Pediatr Infect Dis J 2014; 33(10): 997-1003.

115. Lekhal R, Zachrisson HD, Wang MV, Schjølberg S, von Soest T. Does universally accessible child care protect children from late talking? Results from a Norwegian population-based prospective study. Early Child Development and Care 2011; 181(8): 1007-19.

116. Kamper-Jorgensen M, Benn CS, Simonsen J, Thrane N, Wohlfahrt J. Clustering of acute respiratory infection hospitalizations in childcare facilities. Acta Paediatr 2010; 99(6): 877-82.

117. Stempel HE, Martin ET, Kuypers J, Englund JA, Zerr DM. Multiple viral respiratory pathogens in children with bronchiolitis. Acta Paediatr 2009; 98(1): 123-6.

118. Peltola $\mathrm{V}$, Ziegler $\mathrm{T}$, Ruuskanen $\mathrm{O}$. Influenza $\mathrm{A}$ and $\mathrm{B}$ virus infections in children. Clin Infect Dis 2003; 36(3): 299-305.

119. Tabain I, Ljubin-Sternak S, Cepin-Bogovic J, Markovinovic L, Knezovic I, Mlinaric-Galinovic G. Adenovirus respiratory infections in hospitalized children: clinical findings in relation to species and serotypes. Pediatr Infect Dis J 2012; 31(7): 680-4.

120. Christensen A, Nordbo SA, Krokstad S, Rognlien AG, Dollner H. Human bocavirus commonly involved in multiple viral airway infections. J Clin Virol 2008; 41(1): 34-7.

121. Kuypers J, Martin ET, Heugel J, Wright N, Morrow R, Englund JA. Clinical disease in children associated with newly described coronavirus subtypes.

Pediatrics 2007; 119(1): e70-6.

122. Weinberg GA, Hall CB, Iwane MK, et al. Parainfluenza virus infection of young children: estimates of the population-based burden of hospitalization. $J$ Pediatr 2009; 154(5): 694-9.

123. Edwards KM, Zhu Y, Griffin MR, et al. Burden of human metapneumovirus infection in young children. $N$ Engl J Med 2013; 368(7): 633-43.

124. Yoshida LM, Suzuki M, Nguyen HA, et al. Respiratory syncytial virus: coinfection and paediatric lower respiratory tract infections. Eur Respir J 2013; 42(2): 461-9.

125. Cox DW, Bizzintino J, Ferrari G, et al. Human rhinovirus species $\mathrm{C}$ infection in young children with acute wheeze is associated with increased acute respiratory hospital admissions. Am J Respir Crit Care Med 2013; 188(11): 135864. 
126. Schroeder AR, Mansbach JM. Recent evidence on the management of bronchiolitis. Curr Opin Pediatr 2014; 26(3): 328-33.

127. Gadomski AM, Brower M. Bronchodilators for bronchiolitis. Cochrane Database Syst Rev 2010; (12): CD001266.

128. Saglani S, Payne DN, Zhu J, et al. Early detection of airway wall remodeling and eosinophilic inflammation in preschool wheezers. Am J Respir Crit Care Med 2007; 176(9): 858-64.

129. Berankova K, Uhlik J, Honkova L, Pohunek P. Structural changes in the bronchial mucosa of young children at risk of developing asthma. Pediatr Allergy Immunol 2014; 25(2): 136-42.

130. Pickles RJ, DeVincenzo JP. Respiratory syncytial virus (RSV) and its propensity for causing bronchiolitis. J Pathol 2015; 235(2): 266-76.

131. Tripp RA, Moore D, Barskey At, et al. Peripheral blood mononuclear cells from infants hospitalized because of respiratory syncytial virus infection express T helper- 1 and T helper- 2 cytokines and CC chemokine messenger RNA. J Infect Dis 2002; 185(10): 1388-94.

132. Brand PL, Caudri D, Eber E, et al. Classification and pharmacological treatment of preschool wheezing: changes since 2008. Eur Respir J 2014; 43(4): 1172-7.

133. Dahl R, Bjermer L. Nordic consensus report on asthma management. Nordic Asthma Consensus Group. Respir Med 2000; 94(4): 299-327.

134. McCallum GB, Morris PS, Wilson CC, et al. Severity scoring systems: Are they internally valid, reliable and predictive of oxygen use in children with acute bronchiolitis? Pediatr Pulmonol 2012.

135. Lowell DI, Lister G, Von Koss H, McCarthy P. Wheezing in infants: the response to epinephrine. Pediatrics 1987; 79(6): 939-45.

136. Smith PG, Day NE. The design of case-control studies: the influence of confounding and interaction effects. Int J Epidemiol 1984; 13(3): 356-65.

137. Zorc JJ. Inhaled epinephrine does not shorten hospital stay for infants with bronchiolitis destined to develop repeated bronchospasm. Lancet Respir Med 2015; 3(9): 665-7.

138. Skjerven HO, Rolfsjord LB, Berents TL, et al. Allergic diseases and the effect of inhaled epinephrine in children with acute bronchiolitis: follow-up from the randomised, controlled, double-blind, Bronchiolitis ALL trial. Lancet Respir Med 2015; 3(9): 702-8. 


\section{Errata}

The following changes have been made since submission to the doctoral committee:

Page 45, Table 3: Heading has been cropped from the figure due to wrong table number.

Page 48, Table 5: Heading has been cropped from the figure due to wrong table number.

Page 56, line 3: "Feil! Fant ikke referansekilden." has been replaced with "Table E1, supplementary data to paper \#2"

Page 56, line 10: "Feil! Fant ikke referansekilden." has been replaced with "Table E2, supplementary data to paper \#2"

Page 57, line 2: "Feil! Fant ikke referansekilden." has been replaced with "Table E1, supplementary data to paper \#2"

Page 57, line 4: "Feil! Fant ikke referansekilden." has been replaced with "Table E2, supplementary data to paper \#2"

Page 62: Font size increased to standard, incorrect line break removed. 